\title{
The Epidemic Effect: On the Politics and Economic Burden of Infectious Disease (PRELIMINARY DRAFT) *
}

\author{
Belinda Archibong ${ }^{\dagger}$ \\ Francis Annan \\ Barnard College \\ Georgia State University \\ Uche Ekhator-Mobayode \\ University of Pittsburg Bradford
}

April 7, 2020

\begin{abstract}
Epidemics of infectious disease can have deleterious effects on economic development except mitigated through global health governance and domestic institutions. We investigate this hypothesis by examining the effects of sudden exposure to meningitis on economic outcomes using evidence from the meningitis belt in sub-Saharan Africa. Meningitis shocks reduce economic activity and child health outcomes in periods when the World Health Organization (WHO) does not declare an epidemic year. These effects are reversed when the WHO declares an epidemic year. A primary mechanism explaining the heterogeneity in results may be the influx of donor aid when the WHO declares an epidemic year. We document an increase in World Bank health aid projects approved during epidemic years. Areas that receive more health aid have more economic activity though health projects funded during epidemic years are rated relatively worse by independent evaluators. Domestic institutions influence resource distribution, with regions that are co-ethnic with the president having better outcomes than non-co-ethnic areas. The results are robust to extensive controls and using the timing of the Islamic Hajj to instrument for meningitis shocks.
\end{abstract}

*Thanks to Nancy Qian and participants at the Southern Economics Association conference for useful comments and suggestions. Thanks to Sophie Danzig and Bertina Kudrin for excellent research assistance. The research benefited from conversations with World Bank employees, and we thank them for helpful comments as well. We are grateful to Carlos Perez, Madeleine Thomson, Nita Bharti, the Ministry of Public Health in Niger and the World Health Organization (WHO) for the data on meningitis used in this study. Errors are our own.

$\dagger$ Corresponding author. Barnard College. 3009 Broadway, New York, NY 10027, USA. ba2207@columbia.edu. 
JEL classification: I15, I18, I24, H84, J16, O12

Keywords: Epidemic, Disease, Meningitis, Night Light, Health, Human Capital, Aid, Regional Favoritism

\section{Introduction}

The ongoing coronavirus, COVID-19, pandemic has infected over 1 million people and resulted in more than 50,000 deaths as of April 2020 (Lai et al., 2020). The virulence and human cost of the epidemic, and recent ones like it in the past few decades, has reignited discussions about the economic burden of infectious disease and the steps that can be taken to mitigate their effects. With climate change expected to worsen the incidence of epidemics of infectious disease, estimating the economic burden of disease and the potential role of redistributive efforts to reduce the negative impacts of epidemics is a crucial policy question. While previous research has investigated the economic burden of disease, what is less well understood are the mechanisms that underlie the effects of epidemics on development activity within countries. When countries are declared nationally epidemic by global health governance organizations based on some threshold of cases, the influx of donor aid and reconstruction efforts following the epidemics may increase economic activity, with resultant positive effects on development. Alternatively, if domestic politics exerts an influence, then such reconstruction efforts may have multiplier effects in more politically favored areas and vice versa. Our work provides key insights into these issues.

In this study, we ask two questions: (i) how do epidemics of infectious disease impact economic activity and human capital development? And (ii) what roles, if any, do global health governance and domestic institutions play in mitigating these impacts? Exploiting quasi-random exposure to meningitis shocks and epidemic years in the African meningitis belt, we assemble data on meningitis cases, epidemics, the flow of World Bank donor aid, 
economic activity and child health outcomes to investigate the effects of ostensibly redistributive institutions on the economic burden of epidemic disease. The meningitis belt consists of about 23 countries in Africa, extending from Senegal to Ethiopia and making up over 700 million individuals, that are frequently exposed to meningitis epidemics as shown in Figure 1. The epidemic ${ }^{1}$ form of meningitis is caused by the bacterium Neisseria meningitidis and is characterized by an infection of the meninges or the thin lining covering the brain and spinal cord. Direct transmission is through contact with respiratory droplets or throat secretions from infected individuals (LaForce et al., 2009; García-Pando et al., 2014). Infection is associated with fevers, pain, reduced cognitive function, and in the worst cases, permanent disability and long-term neurological damage and death. Young children and adolescents are particularly at risk of infection and epidemics can be very costly for households, with households in the belt spending up to $34 \%$ of per capita GDP on direct and indirect costs stemming from meningitis epidemics (Colombini et al., 2009; Akweongo et al., 2013).

We exploit quasi-random variation in district level exposure to meningitis shocks and exogenous variation in the announcement of an epidemic year to examine these effects using a difference-in-differences framework. Our meningitis shock variable is constructed from a new dataset, assembling mean weekly meningitis cases per 100,000 population for districts across eight countries in the belt from 1986 to 2008. The shock variable is an indicator that equals one if the z-score for meningitis is above a district's long term mean, following the definition of epidemics outlined by the World Health Organization (Organization, 2020) ${ }^{2}$. We verify the validity of our design by showing that relevant institutional and geographic characteristics are balanced across districts with higher versus lower likelihoods of experiencing meningitis

\footnotetext{
${ }^{1}$ Where epidemics are defined in the SSA context as greater than 100 cases per 100,000 population nationally within a year by the World Health Organization (WHO) (LaForce et al., 2009).

${ }^{2}$ The World Health Organization defines an epidemic as "the occurrence in a community or region of cases of an illness clearly in excess of normal expectancy. The number of cases indicating the presence of an epidemic varies according to the agent, size, and type of population exposed, previous experience or lack of exposure to the disease, and time and place of occurrence." (Organization, 2020).
} 
shocks.

The results show that meningitis shocks or high, unexpected levels of meningitis significantly reduce economic activity on average by $6.5 \%$. The effect is nonlinear, with meningitis shocks increasing economic activity during years declared by the World Health Organization (WHO) as epidemic years and reducing economic activity during non-epidemic years. A meningitis shock during a non-epidemic year decreases economic activity by up to $14.2 \%$, while the announcement of an epidemic year reverses the negative effect, increasing it by up to $2.9 \%$. We find similar results for child health outcomes, with unexpected, high meningitis exposure during epidemic years reducing the incidence of stunting and underweight outcomes in children born during the epidemic year. Children born in meningitis shock areas during a year declared an epidemic year are 6.6 percentage points (pp) less underweight and $7.6 \mathrm{pp}$ less stunted than their non-epidemic year peers. Overall being born in a meningitis shock district during an epidemic year reduces the current incidence of being underweight by 2.3 pp, versus an increase in the incidence of being underweight of up to $4.3 \mathrm{pp}$ for children born in meningitis shock districts in years not declared epidemic years. Similarly being born in a meningitis shock district during an epidemic year reduces the current incidence of being stunted by $3 \mathrm{pp}$, versus an increase in the incidence of being stunted of up to $4.6 \mathrm{pp}$ for children born in meningitis shock districts in years not declared epidemic years. We find some evidence for crowd-out of routine vaccination during epidemic years. Children born in meningitis shock districts during a declared epidemic year are less likely to get BCG (tuberculosis) and polio vaccines.

As a robustness check, and to address potential bias concerns in the measurement of our meningitis shock variable, we use an instrumental variables strategy. Motivated by work from epidemiology and public health which links large gatherings of people at the Hajj, a muslim pilgrimage to Mecca that all muslims are expected to undertake at least once 
during their lifetimes, to outbreaks of meningitis (Lingappa et al., 2003; Shafi et al., 2008; Yezli et al., 2016); and a related literature in economics linking cultural practices to health outcomes (Almond and Mazumder, 2011), we hypothesize that districts with large shares of muslims who happen to be attending the Hajj at the beginning of a meningitis outbreak cycle, may not experience meningitis shocks. The timing of the Hajj is quasi-random and varies yearly according to the Islamic calendar. A combination of social distancing from lowered numbers of people in districts around the Hajj at the beginning of an outbreak cycle, and increased mandatory vaccination rates for Hajj travelers from the meningitis belt at Mecca (Yezli et al., 2016) could significantly decrease infection rates over the course of the cycle (Shafi et al., 2008). Following the predictions of the epidemiological literature, the instrument uses (i) the share of the district that is muslim interacted with (ii) an indicator that equals one if the Hajj happens to fall at the beginning of a meningitis cycle in a given year $^{3}$.

We show that our instrument robustly predicts the meningitis shock variable. Districts with a larger share of muslims potentially departing for Hajj at the beginning of an epidemic cycle have a lower likelihood of being meningitis shock areas. To address possible concerns around the exclusion restriction, we conduct a number of falsification tests, including examining the direct effect of our instrument on our economic outcomes. The results show that our instrument does not directly affect economic activity.

We show that a primary mechanism explaining the heterogeneity in results and the reversal of the negative effect of meningitis shocks on economic activity and child health outcomes during epidemic years is the influx of donor aid when the WHO declares an epidemic year, which may be enough to offset the negative income shock from increased direct and indirect costs resulting from the epidemic. We document an increase in World Bank

\footnotetext{
${ }^{3}$ The beginning of the cycle in meningitis belt countries is January, with cases peaking in March or April and receding in June. We discuss the epidemiology of the disease in further detail in Section 2.
} 
health aid projects approved and funded during epidemic years. The donor effect is redistributive, with funds flowing away from non-health to health sector projects. We find evidence of imperfect targeting of World Bank health aid, due to relatively long approval processes for projects. Areas that receive more health aid have more economic activity. Additionally, health aid projects approved during an epidemic year are rated more poorly by independent evaluators than non-epidemic year health projects.

What roles do domestic institutions play in mitigating the effects of epidemics? Regions with unexpected high levels of meningitis but which share the same ethnicity as the president have higher levels of economic activity and lower proportions of currently stunted and underweight children born during the epidemic year than non-co-ethnic regions. The results confirm trends in previous literature noting the importance of regional favoritism in resource distribution under centralized political institutions (Burgess et al., 2015; Dickens, 2018; Archibong, 2019). This suggests that an additional mechanism may be regional favoritism in within-country resource distribution through domestic institutions. Greater redistribution to co-ethnic affected areas may have multiplicative effects, magnifying and more precisely targeting redistribution of health resources, beyond donor aid. The results highlight the importance of redistributive policy and global and domestic governance around health in mitigating the impacts of epidemics of infectious disease.

We add to several distinct literatures. First, our work is related to the economics literature on the economic burden of infectious disease, and the effects of early life shocks on human capital outcomes (Acemoglu and Johnson, 2007; Adhvaryu et al., 2016; Almond, 2006; Bleakley, 2007; Bloom and Mahal, 1997; Oster, 2005; Jayachandran and Pande, 2017). These studies show that infectious disease can affect a wide range of outcomes, including school enrollment, performance and attainment (Bleakley, 2007; Archibong and Annan, 2017), and labor market outcomes (Almond, 2006; Gould, Lavy, and Paserman, 2011; Bhalotra and 
Venkataramani, 2015), among others.

We also contribute to work in economics, political science and social epidemiology on the role of redistributive institutions and domestic policy in managing the effects of epidemics of infectious disease (Adda, 2016; Chigudu, 2020, 2019; Farmer, 1996, 2001; Geoffard and Philipson, 1996; Krieger, 2001; Leach, Scoones, and Stirling, 2010; Philipson, 1999; Youde, 2017; Copeland et al., 2013). We expand these literatures by providing quantitative estimates of the role of global and domestic redistributive institutions in managing the impacts of epidemics of infectious disease. We also add to the literature on the importance of domestic policy around social distancing in flattening epidemic curves and reducing the severity of outbreaks (Copeland et al., 2013; Fenichel, 2013).

Our work also contributes to the economics literature on the role of donor aid in development (Alesina and Dollar, 2000; Burnside and Dollar, 2000; Easterly, 2006; Nunn and Qian, 2014; Bräutigam and Knack, 2004). While a robust literature has found mixed results on the benefits of foreign aid for development (Burnside and Dollar, 2000; Moyo, 2009), a more recent literature has noted that health aid may have positive impacts on human capital outcomes particularly in asset constrained regions (Odokonyero et al., 2015; Kotsadam et al., 2018; Gyimah-Brempong, 2015; Miguel and Kremer, 2004; Bandiera et al., 2019; Ndikumana and Pickbourn, 2017). Our paper provides quantitative evidence of the barriers to targeting donor aid and adds to the evidence of partial crowd-out that may occur, in areas like routine vaccination, when donor aid increases in response to epidemics of infectious disease (Bloom, Canning et al., 2004; Deserrano, Nansamba, and Qian, 2020; Aldashev, Marini, and Verdier, 2019). Finally, we add to the literature on regional and ethnic favoritism in the distribution of resources (Alesina, Michalopoulos, and Papaioannou, 2016; Alesina, Baqir, and Easterly, 1999; Francois, Rainer, and Trebbi, 2015), and highlight the potential multiplier effects of regional favoritism in domestic redistribution of health resources post an epidemic. 
The rest of the paper is organized as follows. Section 2 provides a brief background on the epidemiology and costs of infectious disease, with a focus on meningitis epidemics. Section 3 describes the data. Section 4 outlines our empirical strategy and presents results on the effects of meningitis epidemics on economic outcomes. Section 5 provides quantitative estimates of the role of World Bank aid as a potential mechanism explaining the results. Section 6 evaluates the role of domestic institutions and regional favoritism. Section 7 concludes.

\section{Epidemics and the Epidemiology of Infectious Disease: Evi- dence from the Meningitis Belt}

The World Health Organization defines an epidemic as "the occurrence in a community or region of cases of an illness clearly in excess of normal expectancy. The number of cases indicating the presence of an epidemic varies according to the agent, size, and type of population exposed, previous experience or lack of exposure to the disease, and time and place of occurrence." (Organization, 2020). Recent epidemics have had costly human capital impacts including: the Ebola epidemic in West Africa, with cases concentrated in Guinea, Liberia and Sierra Leone which resulted in an estimated ${ }^{4}$ 28,600 cases and 11,325 deaths, the 2015 Zika epidemic originating in Brazil and spreading through the Americas, the 2016 dengue epidemic worldwide which resulted in 100 million cases and 38,000 deaths, and most recently, the, as of 2020 ongoing, coronavirus, COVID-19 pandemic, which originated in China and has since spread worldwide resulting in over 1 million cases and more than 50,000 deaths as of April 2020 (Bloom and Cadarette, 2019; Lai et al., 2020).

Although a robust literature in social and economic epidemiology has investigated the economic implications of an increased burden of infectious disease, relatively fewer studies

\footnotetext{
${ }^{4}$ Likely underestimated according to Bloom and Cadarette (2019).
} 
have examined the role of domestic and international health institutions in managing the effects of epidemics (Acemoglu and Johnson, 2007; Adda, 2016; Almond, 2006; Archibong and Annan, 2017, 2019; Deaton, 2003; Jayachandran and Lleras-Muney, 2009). Social epidemiologists in particular have emphasized the importance of ex-ante and ex-post redistributive efforts in health in determining the economic effects of epidemic disease, with studies showing that regions with better and more equitable ex-ante health infrastructure and more, and more equitable distribution of ex-post funding may be able to better manage the effects of epidemics of infectious disease (Farmer, 1996, 2001; Geoffard and Philipson, 1996; Chigudu, 2020; Leach, Scoones, and Stirling, 2010; Bloom, Canning et al., 2004).

A growing literature in economics has highlighted the potential role of targeted redistribution of resources in alleviating the negative effects of infectious disease (Bleakley, 2007; Bandiera et al., 2019; Adhvaryu, Fenske, and Nyshadham, 2019; Adda, 2016; Miguel and Kremer, 2004). While previous studies have examined the impacts of health interventions in targeted randomized control trial settings, there remains relatively little work investigating the role of global health governance institutions in alleviating negative externalities from epidemics of infectious disease (Youde, 2017). To contribute to closing these gaps in the literature on the politics and economic burden of infectious disease, we investigate one of the most virulent and understudied infectious diseases in the world, meningococcal meningitis in the African meningitis belt.

\subsection{The Meningitis Belt}

Meningococcal meningitis is a disease so endemic in the sub-Saharan Africa (SSA) region, that an entire swathe of 23 countries from Senegal to Ethiopia, making up over 700 million individuals, has been labelled the 'meningitis belt' due to frequent exposure to meningitis 
epidemics as shown in Figure $1^{5}$. The epidemic ${ }^{6}$ form of the disease is caused by the bacterium Neisseria meningitidis and is characterized by an infection of the meninges or the thin lining covering the brain and spinal cord. Infection is associated with fevers, pain, reduced cognitive function, and in the worst cases, permanent disability and long-term neurological damage and death. The WHO estimates that about 30,000 cases of the disease are reported each year, with figures rising sharply in regions during epidemic years ${ }^{7}$.

The WHO also states that meningococcal meningitis can have high fatality rates, up to $50 \%$ when left untreated ${ }^{8}$. Although vaccines have been introduced to combat the spread of the disease since the first recorded cases in 1909 for SSA, effectiveness of the vaccines has been limited due to the mutation and virulence tendencies of the bacterium (LaForce et al., $2009)^{9}$. The periodicity of epidemics in the belt differs by country, with epidemic waves in the meningitis belt occurring every 8 to 12 years on average by some estimates (Yaka et al., 2008). Young children and adolescents are especially at risk of infection (Zunt et al., 2018).

The epidemiology of the disease is complex. Direct transmission is through contact with respiratory droplets or throat secretions from infected individuals(LaForce et al., 2009; García-Pando et al., 2014). The bacteria can be carried in the throat of healthy human beings, and, for reasons not completely understood, subdue the body's immune system,

\footnotetext{
${ }^{5}$ The WHO lists 26 countries in total as being at risk for meningitis epidemics, including Burundi, Rwanda and Tanzania (Organization, 2018).

${ }^{6}$ Where epidemics are defined in the SSA context as greater than 100 cases per 100,000 population nationally within a year by the World Health Organization (WHO) (LaForce et al., 2009).

${ }^{7}$ Source: http://www.who.int/mediacentre/factsheets/fs141/en/

${ }^{8}$ http://www.who.int/mediacentre/factsheets/fs141/en/

${ }^{9}$ The most recent vaccine MenAfriVac has been available in meningitis belt countries since 2010 and has been found to be effective against serogroup A, the strain of the bacterium most frequently associated with epidemics in the belt (Karachaliou et al., 2015). There has been a reduction in serogroup A cases in many countries since the introduction of the vaccine with the vaccine hailed as a success. Concerns have been raised about waning herd immunity over the next decade especially if the vaccine does not become part of routine childhood vaccinations; and an increase in serogroup $\mathrm{C}$ cases has been noted in other regions more recently prompting concerns about more epidemics from other serogroups of the bacterium (Karachaliou et al., 2015; Novak et al., 2019). There is currently no vaccine that prevents against all serogroups of Neisseria meningitidis (Yezli et al., 2016).
} 
facilitating the spread of infection through the bloodstream to the brain following a 3 to 7 day incubation period (Basta et al., 2018; Organization, 2018) ${ }^{10}$.

Although epidemic incidence is often associated with higher wind speeds, dust concentrations and lower humidity and temperatures that come with the onset of the dry, Harmattan season in SSA, the mechanisms of transmission are not fully understood ${ }^{11}$ (LaForce $^{-1}$ et al., 2009; García-Pando et al., 2014). The Harmattan season generally extends from October till March, with the harshest part of the season in the first few months from October to December (Perez Garcia Pando et al., 2014). The epidemic curve, as shown in Figure 7, generally follows a sinusoidal pattern in the meningitis belt; cases typically begin in the first month of the year in the dry season in January, and peak around March, with the case load declining rapidly with the onset of the rainy season in June (Lingani et al., 2015).

Documented data on health expenditure of countries in the meningitis belt show that households spend a significant portion of their incomes on direct and indirect costs stemming from meningitis epidemics (Colombini et al., 2009; Akweongo et al., 2013). In Burkina Faso, Niger's neighbor in the meningitis belt, households spent some $\$ 90$ per meningitis case- $34 \%$ of per capita GDP- in direct medical and indirect costs from meningitis infections during the 2006-2007 epidemic (Colombini et al., 2009). In households affected by sequelae, costs rose to as high as $\$ 154$ per case. Costs were associated with direct medical expenses from spending on prescriptions and medicines ${ }^{12}$ and indirect costs from loss of caregiver income (up to 9 days of lost work), loss of infected person income (up to 21 days of lost work) and missed school (12 days of missed school) (Colombini et al., 2009). Meningitis epidemics are

\footnotetext{
${ }^{10}$ The WHO estimates that between $10 \%$ and $20 \%$ of the population carries textitNeisseria meningitidis in their throat at any given time, with carriage rate spiking in epidemic years (Organization, 2018).

${ }^{11}$ The season is characterized by hot, dry northeasterly trade winds blowing from the Sahara throughout West Africa; dust particles carried by the Harmattan winds make the mucus membranes of the nose of the region's inhabitants more sensitive, allowing nasal and throat secretions to spread more easily and increasing the risk of meningitis infection (Yaka et al., 2008).

${ }^{12}$ Vaccines and treatment are technically free during epidemics, however information asymmetry among health care workers and shortages of medicines often raise the price of medication (Colombini et al., 2009).
} 
a notable negative income shock to households in the belt.

\subsubsection{Hajj and Meningitis Epidemics}

Every year more than two million Muslims travel to one of the largest and most geographically and ethnically diverse mass gatherings in the world- Hajj (Ahmed, Arabi, and Memish, 2006; Memish, 2010). Hajj, the annual Islamic pilgrimage to Mecca, Kingdom of Saudi Arabia, spans over a few days in the 12th month of the Islamic lunar calendar (Yezli et al., 2016). Able-bodied adult Muslims who can afford to make Hajj are required to do so at least once in a lifetime. Extended stays and mass gatherings associated with Hajj are a key risk factor influencing outbreaks and transmission of infectious diseases including meningitis (Yezli et al., 2016). To address this risk, authorities of the Kingdom of Saudi Arabia deploy a combination of traditional, and innovative disease surveillance, prevention and control measures for Hajj.

For example, it is mandatory for all pilgrims to be vaccinated with the quadrivalent meningococcal (ACYW) vaccine (Yezli et al., 2016). Additionally, antibiotic prophylaxis is administered upon entry for pilgrims from countries in the meningitis belt (Algarni, Memish, and Assiri, 2019). Compliance with these regulations is enforced by examining vaccination documents at ports of entry to the Kingdom for all pilgrims. These mandatory measures combined with social distancing from fewer number of people in origin countries with a high share of Muslims who perform Hajj could significantly decrease the rate of infection over

the epidemic curve in origin countries if the Hajj, which varies from year to year according to the Islamic calendar, happens to fall at the beginning of a meningitis outbreak cycle in January.

The importance of social distancing- measures taken to reduce physical contact - in reducing the transmission of infectious diseases has been determined to slow down the trans- 
mission of infectious diseases (Copeland et al., 2013). Scientists measure the intensity of an infectious disease by its reproduction number $\left(R_{0}\right)$-the expected number of cases generated by one case- and assert that there is a direct, positive correlation between social interaction and the reproduction number of an infectious disease (Zhang et al., 2020). In the context of the present study, a high share of Muslims in districts in the meningitis belt likely to perform Hajj coinciding with the beginning of an epidemic curve translates to lessened social interaction within those districts and a flattened epidemic curve, which then reduces the likelihood of a district being a meningitis shock district in a given year. We construct a novel instrument to test this hypothesis in Section 4.

\section{Description of Data: Economic Activity, Child Health, Aid and Regional Favoritism}

We combine data from multiple sources for eight countries in the meningitis belt where data on meningitis cases, economic activity and child human capital outcomes were available, namely: Benin, Burkina Faso, Cameroon, Ghana, Mali, Nigeria, Niger and Togo, shown in Figure 2. As of 2019, five (Benin, Burkina Faso, Mali, Niger and Togo) of these eight countries are classified as low-income by the World Bank, while three (Nigeria, Ghana and Cameroon) are classified as low-middle income countries. Estimates of health spending as a share of GDP and the share of donor spending in health expenditure for study countries relative to the Africa and world averages are shown in Figure $6^{13}$.

Note that for the study countries, per capita health spending is relatively low at $\$ 47$ on average, equivalent to $5 \%$ of per capita GDP and lower than both the Africa (5.6\%) and world (10\%) averages. Government spending per capita on health is also quite low at $\$ 11$ and equivalent to $1.1 \%$ of per capita GDP versus $1.3 \%$ for the Africa average and $7.4 \%$ for

\footnotetext{
${ }^{13}$ Estimates from 2016 data, the most recent complete dataset available.
} 
the world mean. Out of pocket spending on health is relatively high at around $50 \%$ of health spending in study countries, and higher than the Africa average (36\%) and the world average (19\%). Donor spending as a share of health expenditures is relatively high at $19 \%$, similar to the Africa average $(20 \%)^{14}$. Further detail on the data is provided in the summary statistics table in Table 1.

\subsection{Meningitis Cases}

We assemble district level records of mean weekly meningitis cases per 100,000 population from the World Health Organization from 1986 to 2008 for countries in the meningitis belt in SSA with available data as shown in Figure $2^{15}$.

Epidemic years of meningitis are declared by the WHO in the sample when the national average incidence of meningitis is above 100 cases per 100,000 population. Table 1 shows that on average, there were 6 meningitis cases per 100,000 for the district/year in our study sample, with significant variability both across and within countries and years as shown in Figure 3. Following the WHO definition of epidemics as "cases of an illness clearly in excess of normal expectancy", we define a meningitis shock variable, as a measure of "outside of normal expectancy" meningitis events at the district level. The meningitis shock variable is an indicator that takes on a value equal to one if meningitis cases in a given year is above the district's standardized long-term mean. In other words, the meningitis shock variable equals one if the z-score relative to the district's long term mean of weekly meningitis cases per 100,000 population is greater than zero. The average share of districts classified as meningitis shock districts is around 0.36 as shown in Table 1 .

\footnotetext{
${ }^{14}$ Complete data on donor spending for the entire world sample is not available for the 2016 year.

${ }^{15}$ District level weekly cases of meningitis case per 100,000 population are available from 1995 to 1999 for 28 districts in Benin, 1996 to 1999 for 30 districts in Burkina Faso, 1997 to 1998 for 10 districts in Cameroon, 1996 to 1998 for 138 districts in Ghana, 1989 to 1998 for 80 districts in Mali, 1986 to 2008 for 34 districts in Niger, 1995 to 1997 for 116 districts in Nigeria and 1990 to 1997 for 59 districts in Togo as shown in Figure 3. These make up a dataset of district level meningitis cases of 495 districts across the 8 countries.
} 


\section{$3.2 \quad$ Night Lights}

Following previous literature using night light density as a proxy for economic activity (Henderson, Storeygard, and Weil, 2011; Michalopoulos and Papaioannou, 2013), we use data on night light density from the National Oceanic and Atmospheric Administration (NOAA) Defense Meteorological Satellite Program's Operational Linescan System (DMSP-OLS) to measure economic activity in the absence of detailed micro-level income estimates for the study countries. Night light density data from the NOAA is available from 1992, and we use data from 1992-2008 to match meningitis case data from our study region. Since a notable fraction of the district level observations take on the value of zero, following previous literature, we use the log of night light density, adding a small number (ln (0.01+ LightDensity)) as our measure of night light density. The log transformation allows us to use all observations and account for outliers in the luminosity data (Michalopoulos and Papaioannou, 2013).

\subsection{Child Health}

To examine the effects of epidemics on child health outcomes, we use geocoded data from the birth recode (BR) of the Demographic and Health Surveys (DHS) for various years for the 8 countries. The DHS data are nationally representative cross-sectional household surveys that provide information on the demographic characteristics of individuals within households. For the BR sample, women aged 15-49 are individually interviewed to gather information on every child ever born to the woman. For each of the women interviewed, the BR has one record for every birth ${ }^{16}$.

For births within the past five years at the time of each survey, the DHS data contains

\footnotetext{
${ }^{16}$ The BR of the DHS, including important geocoded information on the location of households or household clusters, is available for 1996, 2001 and 2012 for Benin; 1999, 2003 and 2010 DHS for Burkina Faso; 2004 and 2011 DHS for Cameroon; 1998, 2003, 2008 and 2014 DHS for Ghana; 1996, 2001, 2006 and 2012 DHS for Mali; 1992 and 1998 DHS for Niger; 2003, 2008 and 2013 for Nigeria; and 1998 and 2013 for Togo.
} 
information on child anthropometric outcomes including the weight for age z score (WFA z) and height for age z score (HFA z), vaccinations, and mortality status - whether child is alive or dead and age at death if dead. Combined with the district level meningitis cases, this gives a dataset of nationally representative individual level data of births from 1992 to 2014 covering 14 DHS surveys across the 8 countries. The average infant mortality, or rate of children who die within the year of birth, in the sample is $38 \%$. The average WFA z and HFA $\mathrm{z}$ are -1.54 and -1.47 respectively. In normal circumstances, regardless of spatial differences, children in normal conditions should have similar anthropometric indicators (Habicht et al., 1974).

The WFA $\mathrm{z}$ and HFA $\mathrm{z}$ reflect factors that may affect a child's health in utero, at birth and/or after birth. Higher values are generally associated with favorable health conditions (Jayachandran and Pande, 2017). A child is considered underweight with a WFA z of less than -2.0 while a child is considered stunted with a HFA $\mathrm{z}$ of less than $-2.0 .38 \%$ of children in the sample are underweight while $36 \%$ are stunted. Finally, we examine child vaccination rates for routine vaccines as indicators of healthcare use. We collect available information on BCG (tuberculosis), polio, DPT (diphtheria, pertussis and tetanus) and measles vaccination as well as a total of all vaccinations. $61 \%$ and $42 \%$ percent of children in the sample received BCG and measles vaccination respectively. Of the 3 doses of polio and DPT vaccinations required, children received an average of 1.45 and 1.38 doses respectively. The average total number of vaccines received by children in the sample was 3.83 out of a maximum of 8 vaccines as shown in Table 1 . Note the recommended schedule for routine vaccination of children by WHO standards is at birth for BCG and with the first dose at birth for Polio as shown in Table 2, in contrast with DPT and measles which may be taken later after birth (Organization, 2019). 


\subsection{World Bank Aid Data}

To examine the relationship between epidemics and global governance health interventions/initiatives, we use geocoded data on World Bank funded projects by sectors from AidData. This data contains the location and sectors of World Bank funded projects between 1995 and 2014 (AidData, 2017) as shown in Figure 5. Projects are classified by the World Bank as belonging to up to 5 sectors, such as: health, central government administration, general public administration, other social services, railways, and roads and highways. The amount (in 2011 USD) committed and disbursed for each project is also reported. A subset of these projects is given an independent evaluation grade (IEG) or project outcome rating based measuring the extent to which the major relevant objectives of the project were achieved, or are expected to be achieved, efficiently.

This rating is on a six-point scale ranging from highly unsatisfactory (1) to highly satisfactory $(6)^{17}$. We limit our sample to the subset of projects approved during between 1986 to 2008 to match the duration of our meningitis case data. Summary statistics in Table 1 show that while on average around $\$ 56$ million is committed to projects approved during our study years, only $12 \%$ of projects are health projects, where we define a project as being in the health sector if any one of its 5 sector categories correspond to health. The average committed for health projects is relatively lower at around $\$ 6$ million per year. The average duration of these projects is around 6 years, while their average IEG rating is 3.98, or around 4 or "moderately satisfactory".

\footnotetext{
${ }^{17}$ In detail: "Highly Unsatisfactory"="1", "Unsatisfactory"="2", "Moderately Unsatisfactory"="3", "Moderately Satisfactory"="4", "Satisfactory"="5", "Highly Satisfactory"="6".
} 


\subsection{Regional Favoritism}

To examine the role of regional favoritism in determining the distribution of resources following an epidemic, we rely on the president's recorded ethnic group to determine a president's ethnicity and data from the geo-referencing of ethnic groups (GREG) intersected with district shapefiles to determine if any of the district's population shares the ethnicity of the president, following the recent literature emphasizing the importance of broad coalitions of ethnic affiliations for redistribution of public goods and services from the center along ethnic lines in Africa (Hodler and Raschky, 2014; Dickens, 2018). We present data and results from Niger where we have the most complete data on the president's ethnicity and origin here.

\section{Estimating the Effects of Meningitis Epidemics on Economic Activity and Child Health Outcomes}

\subsection{Intuition and Sources of Variation}

The intuition for our identification strategy is straightforward. We exploit two sources of variations: one is the variation created when countries are declared [nationally] epidemic based on the aggregate distribution of meningitis cases "Epidemic Year" which is arguably exogenous to observed district level realizations of meningitis, and the other is a "Meningitis Shock" reflecting unusually high cases of meningitis at the district level. In practice, we explore two constructions for "Meningitis Shock": one reflecting the district-level meningitis $z$ scores -ie., district meningitis positive deviations from their long-run average, and the other capturing district's meningitis positive deviations from their long-run (moving) average. We present the results from the $\mathrm{z}$-score specification in the main text ${ }^{18}$. The intuition behind defining meningitis shock in these ways, as stated earlier, follows the WHO definition of an

\footnotetext{
${ }^{18}$ The results from both constructions are qualitatively similar, and we present results from the long-run average in the Appendix.
} 
epidemic, such that an individual district may be experiencing epidemic levels of meningitis cases relative to its expectation, but the national average does not rise to the level that the WHO chooses to declare a country-wide epidemic.

Our "Meningitis Shock" measures are also plausibly quasi-random for three reasons: (i) there is significant variation in meningitis cases within country-districts, (ii) there are no obvious trends in meningitis cases, and (iii) the "Meningitis Shock" measures are uncorrelated with district-level observables as shown in the balance table estimates in Table 3. Together, these suggest that our "Meningitis Shock" constructions are not picking up any endogenous differences between districts; thus likely capturing exogenous variations from un-anticipated exposure to meningitis outbreaks. We outline the model specification in Section 4.2. We address potential concerns about the validity of the design in Section 4.3 and outline the instrumental variables strategy in Section 4.4. .

\subsection{Model Specification}

We begin with a simple panel regression model linking changes in nightlights $y_{d t}$-- our measure of local economic development activity, to two sources of epidemic variations. For other micro or household-level outcomes that we investigate, nightlights is replaced with those outcomes accordingly, with outcomes measured at the individual child level $i$. We estimate for district $d$ in country $c$ and (health) year $t$ :

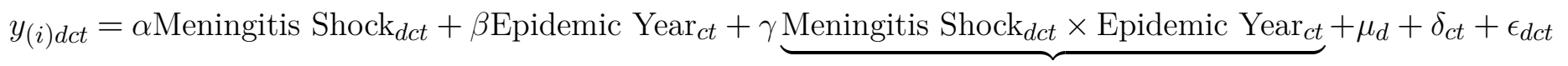

where "Meningitis Shock" is an indicator for a district's positive deviations from its long-run average of mean weekly meningitis cases per 100,000 population. "Epidemic Year" 
is an indicator for whether the WHO declares an epidemic year in a particular country. This specification includes a set of unrestricted within-country district dummies, denoted by $\mu_{d}$, which capture unobserved differences that are fixed across districts. The country-year fixed effects, $\delta_{c t}$ control for aggregate changes that are common across countries over time, e.g. aggregate prices, and national policies. In model specifications with current child health as the outcomes, we also include year of birth fixed effects to account for potential life cycle changes across cohorts.

Our key parameter of interest $\gamma$ is identified by district-level variation in "Meningitis Shock" and variation from whether or not the WHO declares a nation $c$ 's year $t$ as epidemic. This provides an estimate of the "epidemic effect": how meningitis epidemics and the global and national response affect economic activity and is identified based on standard assumptions in a difference-in-differences model. Errors are clustered at the district level to allow for arbitrary correlations.

Next, to assess the potential role of ethnic favoritism and its allocative effects on meningitis epidemics, we modify the baseline model to include an interaction for whether or not the president hails from an ethnic group of district $d$, "Same Ethnicity":

$y_{(i) d t}=\alpha$ Meningitis Shock $_{d t}+\beta$ Same Ethnicity $_{d t}+\gamma \underbrace{\text { Meningitis Shock }_{d t} \times \text { Same Ethnicity }_{d t}}+\mu_{d}+\delta_{t}+\epsilon_{d t}$

In practice, we define "Same Ethnicity" as a simple indicator of districts that contain a non-zero share of people who share the same ethnicity as the president in year $t$, following the recent literature on ethnic favoritism (Hodler and Raschky, 2014; Dickens, 2018). We restrict our analysis for ethnic favoritism and meningitis allocation to only Niger: we have complete reliable data on presidents' ethnicity only in Niger; ethnicity data for other countries in our 
sample is sparse and incomplete.

\subsection{Balance and Validity of Design}

The difference-in-differences strategy outlined in Equation 1 and Equation 2 requires one important identifying assumption; that all relevant factors before epidemic years varied evenly between meningitis shock and non-meningitis shock districts. This assumption is needed to ensure that, ex-ante, pre-epidemic exposure, individuals located in meningitis shock districts are an appropriate counterfactual for those located in unaffected districts. To evaluate the plausibility of the first assumption, we estimate simple regressions of the likelihood of being a meningitis shock district, measured as our meningitis shock variable averaged over the years of available data for each district in each country, on a number of geographic and institutional characteristics for each district following the below specification:

$$
y_{d c}=\alpha+\xi \mathbf{M}_{d c}+\delta_{c}+\epsilon_{d c}
$$

where $\mathbf{M}_{d c}$ is district $d$ 's likelihood of being a meningitis shock district over the study period. We consider various outcomes, $y_{d c}$, spanning geographic and institutional features, following previous literature on the relevance of these characteristics for development (Michalopoulos and Papaioannou, 2013; Archibong, 2019). The results in Table 3 show no observable differences in outcomes across districts that experienced more meningitis shocks between 1986 and 2008 and those that did not.

\subsection{Instrumental Variables Strategy}

As a robustness check, and to address potential bias in the measurement of our meningitis

shock variable, we use an instrumental variables strategy. If the meningitis case survey data underlying the shock variable is measured with error, for instance, because of discrepancies 
in reporting functionality at health facilities providing data to the WHO during shock years, this may bias our estimates of the effects of meningitis shocks on economic outcomes. If, for instance, reporting capability is negatively impacted during shock years, then our estimates may be biased downward, and the results from the OLS could be underestimating the effects of meningitis shocks on economic activity. Motivated by work from epidemiology and public health which links large gatherings of people at the Hajj to outbreaks of meningitis (Lingappa et al., 2003; Shafi et al., 2008; Yezli et al., 2016); and a related literature in economics linking cultural practices to health outcomes (Almond and Mazumder, 2011), we hypothesize that districts with large shares of muslims who happen to be attending the Hajj at the beginning of a meningitis outbreak cycle, may not experience meningitis shocks.

The timing of the Hajj is quasi-random and varies yearly according to the Islamic calendar $^{19}$. A combination of social distancing from lowered numbers of people in districts around the Hajj at the beginning of an outbreak cycle, and increased mandatory vaccination rates for Hajj travelers from the meningitis belt at Mecca (Yezli et al., 2016) could significantly decrease infection rates over the course of the cycle (Shafi et al., 2008). Following the predictions of the epidemiological literature, the instrument uses (i) the share of the district that is muslim interacted with (ii) an indicator that equals one if the Hajj happens to fall at the beginning of a meningitis cycle in January in a given year.

\subsection{Results for Night Light Density}

Figure 8 shows a snapshot of our economic activity results, with log night light density higher in meningitis shock districts during a declared epidemic year, while the results for night lights and our child health outcomes are summarized in Figure 9.

Table 4 reports estimates from Equation 1 with the night light density outcome. On

\footnotetext{
${ }^{19} \mathrm{~A}$ list of Hajj months over our meningitis survey years is in Table A6.
} 
average, meningitis shocks reduce economic activity, as measured by night light density, by $6.5 \%$ as shown in column (1). The effect is nonlinear, as shown in the fully specified model in column (4), where high levels of meningitis shocks increase economic activity by around $17.1 \%$ in epidemic years and reduce economic activity by $14.2 \%$ in non-epidemic years. The effect of meningitis shocks during epidemic years is effectively reversed, with an increase in economic activity of up to $2.9 \%$ in meningitis shock districts during declared epidemic years.

The results are striking, in that though the average effect of meningitis shocks is negative, there is significant heterogeneity in the effects of these disease shocks depending on whether or not the WHO declares an epidemic year. Given the high share of health expenditure sourced from donor aid in the majority of the study countries as shown in Table 6, a major mechanism explaining this result is an influx of donor aid when the WHO declares an epidemic year. Two potential mechanisms that may explain these results are (i) when the WHO declares an epidemic year, there is an influx of donor aid, which may boost investments in health and other infrastructure, leading to an increase, overall in economic activity, despite health costs associated with treating epidemics; and (ii) Following the regional/ethnic favoritism literature, presidents are more likely to redistribute domestic resources to co-ethnic areas, particularly during non-epidemic years, when no outside investments/donor aid is increased following an epidemic year designation.

\subsection{Results for Child Health Outcomes}

Table 5 reports estimates for the current HFA $\mathrm{z}$ and WFA z outcomes along with estimates of infant mortality and current stunting and underweight outcomes. While there is no significant effect of the interaction for meningitis shock and the epidemic year for infant mortality, children born in meningitis shock districts during an epidemic year are taller (column 2) and weigh more (column 4) than their peers born into meningitis shock but non-epidemic year districts. Children born in high meningitis, meningitis shock areas during 
a year declared an epidemic year are 6.6 percentage points less underweight, 7.6 pp less stunted than their meningitis shock, non-epidemic year peers. Overall being born in a high meningitis/meningitis shock district during an epidemic year reduces the current incidence of being underweight by $2.3 \mathrm{pp}$, versus an increase in the incidence of being underweight of up to $4.3 \mathrm{pp}$ for children born in high meningitis shock districts in years not declared epidemic years.

Similarly being born in a high meningitis/meningitis shock district during an epidemic year reduces the current incidence of being stunted by $3 \mathrm{pp}$, versus an increase in the incidence of being stunted of up to $4.6 \mathrm{pp}$ for children born in high meningitis shock districts in years not declared epidemic years. The results here shed light on the medium to long-run impacts of the WHO declaration of an epidemic year, with a potential mechanism being, as mentioned previously, an influx of donor health aid post the announcement of an epidemic year.

Table 6 reports estimates for child current immunization outcomes, classified by immunizations recommended at birth (BCG, polio) versus immunizations recommended sometime after birth (DPT, measles) as mentioned previously and reported in Figure 2. The results here are quite different to the earlier results on positive reversals for health in meningitis shock districts during the epidemic year. For child routine vaccination, the results show significant negative effects of meningitis shock on BCG and the number of polio doses (at birth) vaccinations, with the signs negative but not significant for DPT and measles or nonat birth vaccinations. Here, routine vaccination for BCG is up to 4.7 pp higher for children born in meningitis shock districts during non-epidemic years and, overall, $2.1 \mathrm{pp}$ lower for children born in meningitis shock districts in declared epidemic years. A similar significant pattern is shown for the polio vaccine in column 2 as well. One potential explanation for these patterns is, following the donor aid literature that suggests that health aid from donor agencies in response to epidemics/during epidemic years, may crowd-out routine vaccination, 
that there is crowd-out of routine vaccines in years declared epidemic years. The effect is then particularly strong for vaccines that should be administered at or close to the time of birth $^{20}$ (Deserrano, Nansamba, and Qian, 2020; Boone, 1996; Bräutigam and Knack, 2004).

\subsection{Instrumental Variable Estimates: Night Light Density}

The results presented in Table 4 to Table 6 suggest that meningitis shocks have nonlinear effects on economic outcomes, reducing economic activity in non-epidemic years and vice versa. As discussed in Section 4.4, the OLS estimates of the effect of meningitis shocks on economic activity may be biased if there is some measurement error in our meningitis shock variable. To address this concern, we present results using an instrumental variables strategy. A plausible instrument will predict exposure to meningitis shocks but will not affect economic activity, except through the meningitis shock measure.

Following the research in epidemiology and public health on the role of the Islamic Hajj in meningitis outbreaks outlined in Section 2.1.1, we construct an instrument that is the interaction between two components: (i) the share of the district that is muslim interacted with (ii) an indicator that equals one if the Hajj happens to fall at the beginning of the meningitis cycle in January in a given year.

The share of the district that is muslim is based on mothers' responses to the religion question in DHS women's sample and is averaged over all years for each district. Although sampling is not based on religion, the muslim share is stable across individual survey years, with correlation coefficients ranging from 0.65 to $0.98(p<.001)$ across study countries $^{21}$. The intuition here, from the epidemiological literature, is that since the timing of the Hajj is quasi-random and varies yearly according to the Islamic calendar, districts with large shares

\footnotetext{
${ }^{20}$ Which is why we would expect to see no effects for measles, for example, which should be administered at 9 months.

${ }^{21}$ Correlations are based on the two most recent years of data for each country, to alleviate concerns of fewer observations in earlier years.
} 
of muslims who happen to be attending the Hajj at the beginning of a meningitis outbreak cycle, may not experience meningitis shocks. A combination of social distancing from lower numbers of people in districts around the Hajj at the beginning of an outbreak cycle, and increased mandatory vaccination rates for Hajj travelers from the meningitis belt at Mecca (Yezli et al., 2016) could significantly decrease infection rates over the course of the cycle (Shafi et al., 2008).

Panel A of Table 8 presents the first stage estimates for the Share Muslim x Hajj interaction instrument. The instrument significantly predicts meningitis shocks, with an F-stat greater than 10 in all specifications. Panel B of Table 8 presents the second stage estimates for night light density as the dependent variable ${ }^{22}$. The IV results qualitatively support the OLS results for night light density. Meningitis shocks increase night light density by $10.5 \%$ in declared epidemic years in the IV specification in Column (3) of Panel B versus a $62 \%$ decrease in economic activity in non-epidemic years. The corresponding OLS estimates are a $2.9 \%$ increase in epidemic years versus a $14.2 \%$ decrease in economic activity in non-epidemic years. The difference in the magnitude of the IV estimates could suggest measurement error in the meningitis shock variable, where the shock indicator is an imperfect proxy for unexpected exposure to high levels of meningitis in our sample.

\section{The Role of Health Aid: Evidence from World Bank Projects}

One key mechanism that may explain both the positive reversal in economic activity and child health outcomes and the crowd-out of routine vaccination results in Section 4.6 is an inflow of donor aid post the announcement of an epidemic year. To investigate this hypothesis we use aid data from World Bank projects as described in Section 3.4. We first estimate the

\footnotetext{
${ }^{22}$ Since the only years in the sample for which Hajj falls in January at the beginning of the outbreak cycle are 2005 and 2006 as shown in Table A6, we are unable to estimate child health outcomes with the instrument. There are no countries in the sample which have both complete meningitis data and DHS data on children born in Hajj years.
} 
models in Equation 1 using World Bank aid data as our outcomes of interest. Then as a robustness check, we perform heterogeneity analysis using the share of world bank aid and using economic activity as our outcome variable to see if shock districts that get more World Bank aid have more economic activity than their non aid recipient counterparts.

\subsection{How World Bank Projects are Approved and Funded}

To understand the results, it is important to understand how World Bank projects are funded. We spoke to numerous officials and employees at the World Bank to get insight on how World Bank aid projects are approved and funded. Our research revealed that projects take relatively long times to be approved, with estimates of an average of 7-12 months to approve a single project. Projects must go through 'concept approval, final design approval, then final package to Board' before possibly being approved and funded. The shortest amount of time to approve projects in an 'emergency' setting is reported to be around 3 to 4 months. A snapshot of the World Bank project approval process is provided in Figure 10.

What this means is that locations for World Health projects are chosen ex-ante relative to the declaration of an epidemic year, and can be quite sticky and difficult to target specific areas ex-post ${ }^{23}$ (Öhler et al., 2017). This affects the targeting of health aid, given the relatively small amount of health aid projects funded in the sample (12\%), where officials are not able to perfectly target health aid to districts or areas that may be most in need during an epidemic year.

\footnotetext{
${ }^{23}$ Öhler et al. (2017) provide suggestive evidence that projects are targeted geographically by population share, with more populous regions receiving more projects, rather than by poverty status.
} 


\subsection{Results: Health Project and Non Health Funding in Epidemic vs Non- Epidemic Years}

Table 9 reports the first set of estimates showing the impacts of meningitis shocks in epidemic and non-epidemic years on the share of World Bank health aid projects approved and funded. In column (1), when an epidemic year is declared, there is a significant increase, up to 82 pp, in health projects approved in that year. Column (4) shows that there is no significant difference in health projects approved to meningitis shock vs non shock districts, which may be explained by the inability to target issues discussed in Section 5.1 .

While there is an increase in total dollars committed and disbursed to health projects during epidemic years, as shown in Table 10, the effect does not significantly differ between meningitis shock and non-meningitis shock districts, suggesting lack of targeting, as mentioned previously. Also note that the results suggest a redistribution of aid funds from non-health to health projects, with positive, significant signs in epidemic years for the total amount of funds committed and disbursed to health projects, and negative signs on amounts going to non-health projects. Lastly, Table 11 shows a decrease in the independent evaluator

rating (IEG) of projects started during the epidemic year (column (2)). Health projects started during the epidemic year are rated worse than their non-epidemic year counterparts as shown in column (3).

As a robustness check in Table 12, meningitis shock districts that receive a greater share of health aid projects approved in the year and more health aid committed and disbursed see an increase in their economic activity as measured by night light density as shown in columns (1)-(3). The effect is driven by health specific aid not general/total aid as shown in columns (4) and (5).

Though there is no publicly available data on the details of the projects approved 
over the study period, the dataset includes project titles that provide suggestive evidence on the kinds of health and non-health projects being funded in epidemic vs non epidemic

years. A snapshot of the top 5 titles in each period is provided in Figure 11. Notable is the difference between the epidemic and non epidemic year health project titles funded. During the epidemic year the top health project titles are 'health sector and development program' and 'Economic recovery and adjustment credit (ERAC) project', while during non-epidemic years, the top project titles are 'Community acton program', 'social fund' and 'health, fertility and nutrition project', providing strong suggestive evidence of the responsiveness of World bank donor health aid to epidemic year announcements.

\section{Domestic Institutions: Regional Favoritism and Epidemics}

\subsection{Within Niger Evidence}

To explore the role of domestic institutions on redistribution efforts in response to epidemics of infectious disease, we use data on the ethnic match between the president and a district. Following the regional favoritism literature, we test the hypothesis, that regions that share an ethnicity or are co-ethnic with the president, have better economic outcomes than non-coethnic districts possibly due to redistribution of resources toward co-ethnic districts (Alesina, Baqir, and Easterly, 1999; Alesina, Michalopoulos, and Papaioannou, 2016; Dickens, 2018; Francois, Rainer, and Trebbi, 2015; Hodler and Raschky, 2014). Given previous literature on the increased salience of redistributive tension among groups for more asset constrained entities, we focus on the poorest country for which we have the most complete data on meningitis and ethnicity in our sample, Niger (Archibong and Annan, 2017, 2019). 


\subsection{Regional Favoritism Results}

We estimate the model from Equation 2, and document results for the impacts of meningitis shock on economic activity in epidemic vs non-epidemic years and co-ethnic vs non-coethnic districts in Table 13. On average, meningitis shocks, reduce economic activity, as measured by night light density, by $8.5 \%$. The effect is nonlinear, as shown in column (3), where meningitis shocks increase economic activity by around $6 \%$ in epidemic years and reduce economic activity by $17 \%$ in non-epidemic years. There is also heterogeneity in the effect of meningitis shocks on economic activity by whether or not the president shares the same ethnicity as the district in a given year as shown in column (5). Districts with which the president shares the same ethnicity, experience a smaller decrease in economic activity when there are high levels of meningitis shocks than non-co-ethnic districts. Column (6) shows the combined effect of having high levels of meningitis shocks in an epidemic year, if a district is co-ethnic with the president- an increase of up to $11 \%$ in economic activity.

Table 14 shows the split sample results by epidemic year for economic activity. The effect of being co-ethnic with the president on economic activity is positive in epidemic and non-epidemic years, and significantly positive in non-epidemic years, suggesting that even in the absence of external donor aid, the executive branch attempts to invest its resources in co-ethnic areas that are hardest hit by high unexpected levels of meningitis ${ }^{24}$.

The split sample results for child health outcomes in Table 15 are similar to the economic activity results, though the effect of co-ethnicity on reducing infant mortality, and current underweight and stunting incidence is only significant during epidemic years. This result is consistent with a lack of health aid or influx of health funding in response to meningitis shocks outside of an epidemic year. Interestingly, there is no crowd-out during epidemic years for meningitis shock areas that are co-ethnic with the president as shown in Table 16,

\footnotetext{
${ }^{24}$ The sign is not significant in the epidemic year split sample possibly due to low sample size and power.
} 
suggesting even greater redistribution to those areas may be occurring during the epidemic year, beyond the magnitude suggested by donor aid discussed in Section 5 .

\section{Conclusions}

Recent scientific literature have provided evidence that future warming and climate change may significantly increase the incidence and alter the geographical distribution of epidemics of infectious disease. This may have potentially devastating consequences for global welfare, absent effective redistributive institutions aimed at improving human capital outcomes.

An important contribution of our paper is to provide quantitative estimates of the effects of epidemics of infectious disease on economic and human capital outcomes. We examine the role of donor aid in determining the distribution of resources following the announcement of an epidemic year. We find that high, unexpected levels of meningitis significantly reduce economic activity on average. The effect is nonlinear, with meningitis shocks increasing economic activity during years declared by the World Health Organization as epidemic years and reducing economic activity during non-epidemic years. A meningitis shock during a non-epidemic year decreases economic activity, while the announcement of an epidemic year reverses the negative effect. We find similar results for child health outcomes, with unexpected, high meningitis exposure during declared epidemic years reducing the incidence of stunting and underweight outcomes for children born during the epidemic year. Children born in meningitis shock areas during a year declared an epidemic year are less underweight and less stunted than their non-epidemic year peers.

The results are robust to extensive controls and instrumenting for meningitis shock using the timing of the Hajj which provides quasi-random variation in social distancing measures essential for flattening epidemic curves. The Hajj strongly predicts meningitis shock districts in areas with high shares of muslim population and reduces the likelihood of 
a district experiencing a meningitis shock.

We show that a primary mechanism explaining the heterogeneity in results and the reversal of the negative effect of meningitis shocks on economic activity and child health outcomes during epidemic years is an influx of donor aid when the WHO declares an epidemic year, which may be enough to offset the decline from increased direct and indirect costs resulting from the epidemic. We document an increase in World Bank health aid projects approved and funded during epidemic years. The donor effect is redistributive, with funds flowing away from non-health to health sector projects. Areas that receive more health aid have more economic activity. Regions with unexpected, high levels of meningitis but which share the same ethnicity as the president have higher levels of economic activity, and better child health outcomes, suggesting that another mechanism may be regional favoritism in resource distribution. The results highlight the importance of global governance around health and domestic redistributive policy in mitigating the negative impacts of epidemics of infectious disease on economic outcomes. 


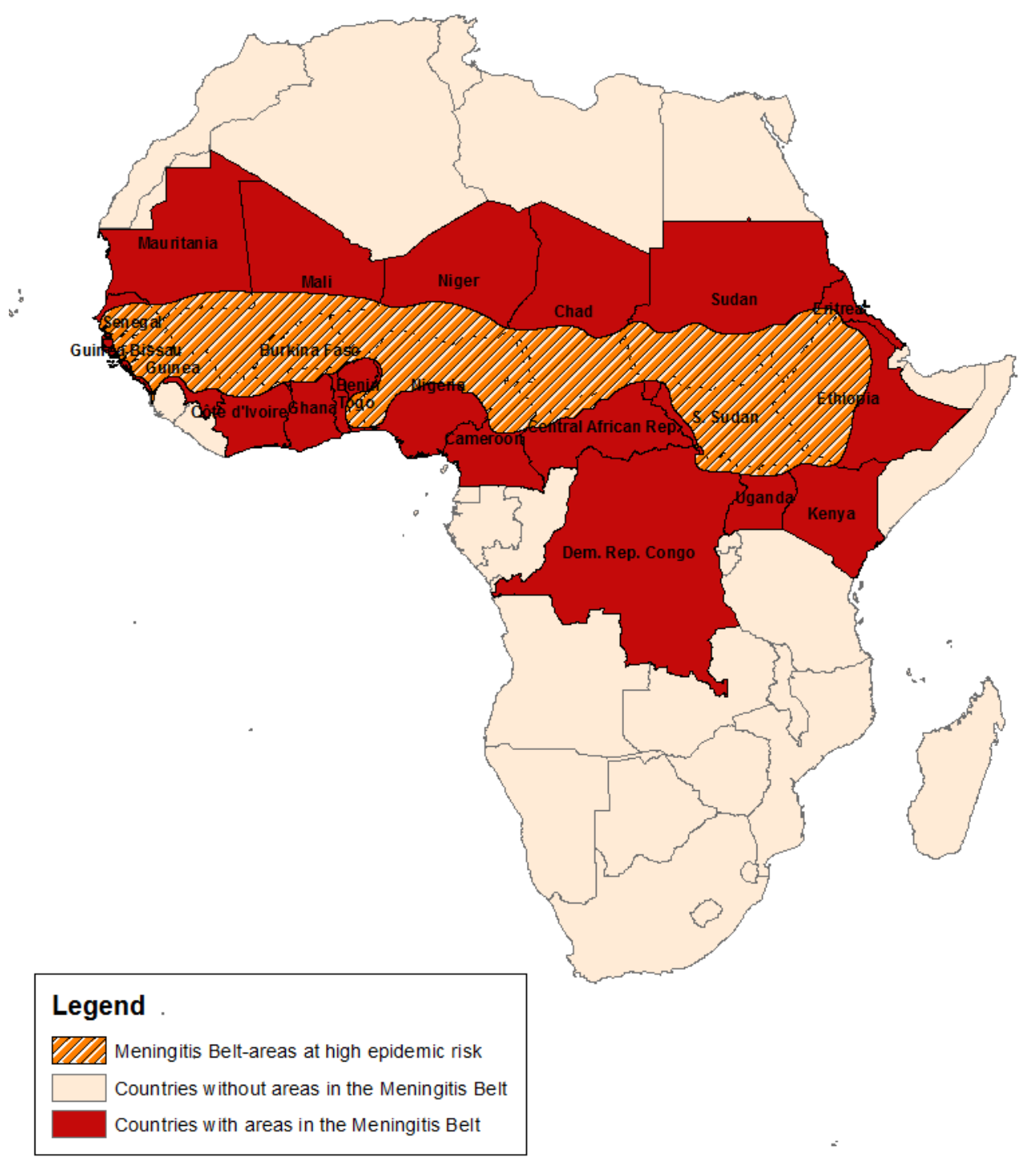

Figure 1: Countries in the African Meningitis Belt 


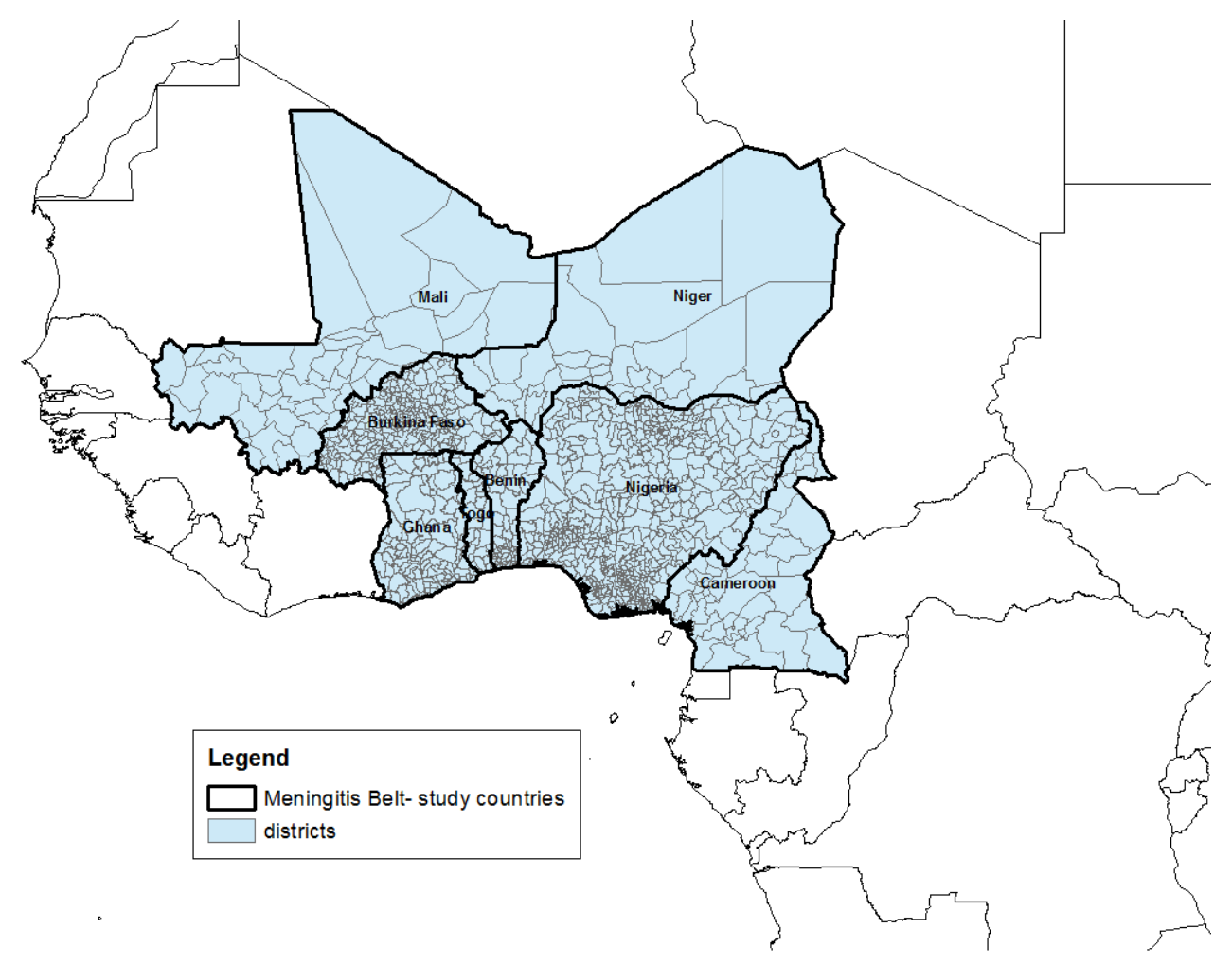

Figure 2: Countries and districts in study region

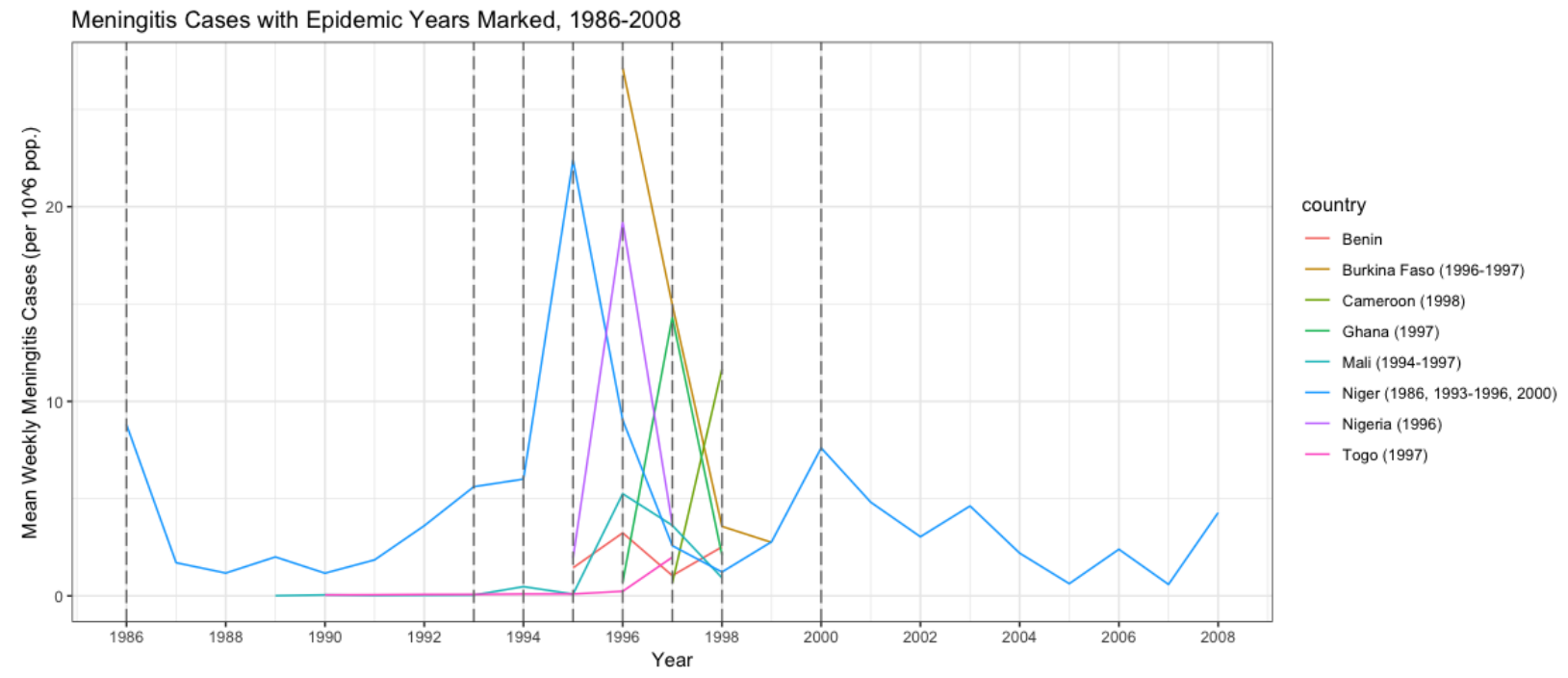

Figure 3: Mean weekly meningitis cases per district over study region, with epidemic years specified in brackets 

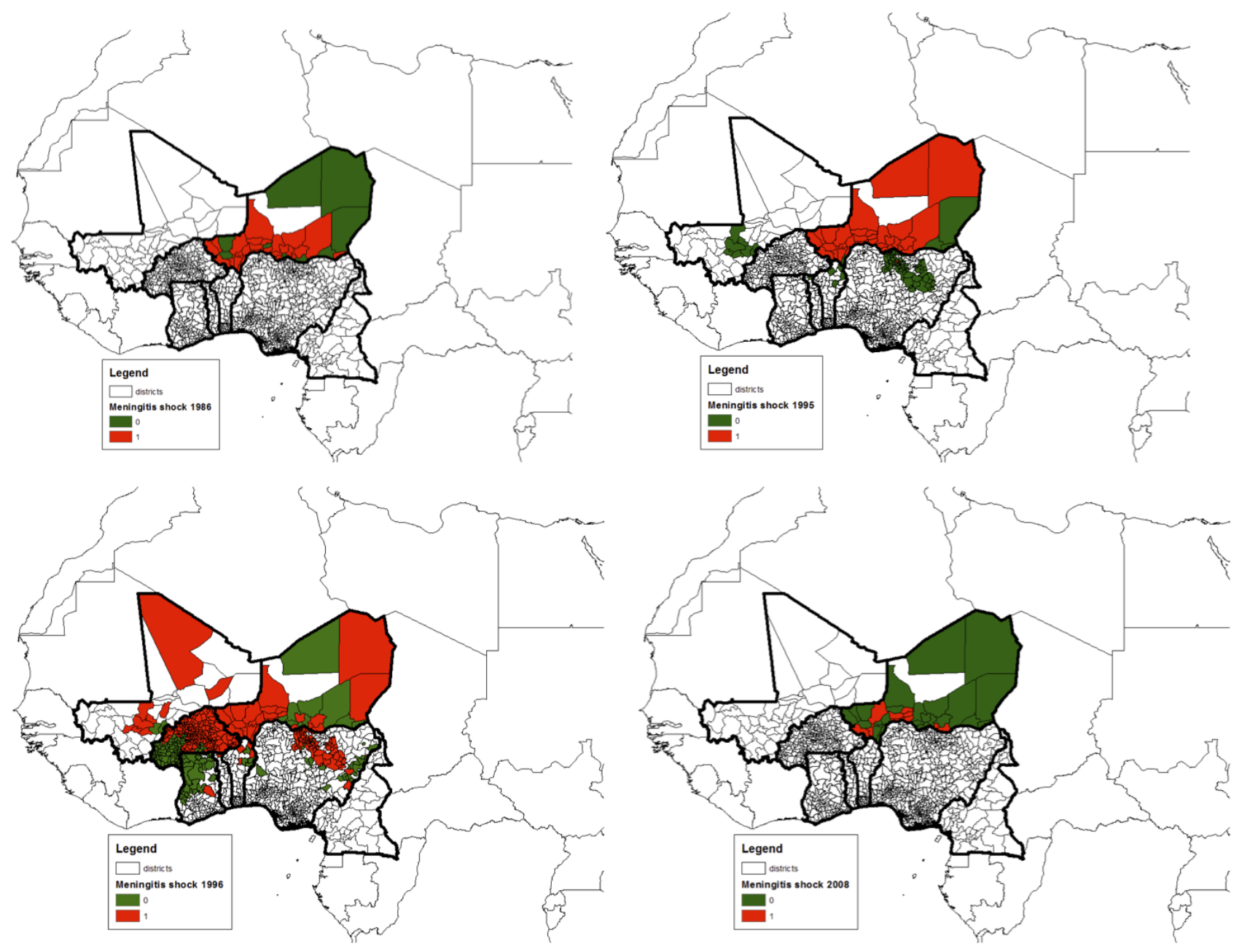

Figure 4: Spatial distribution of meningitis shock over study districts for selected years, 1986-2008 


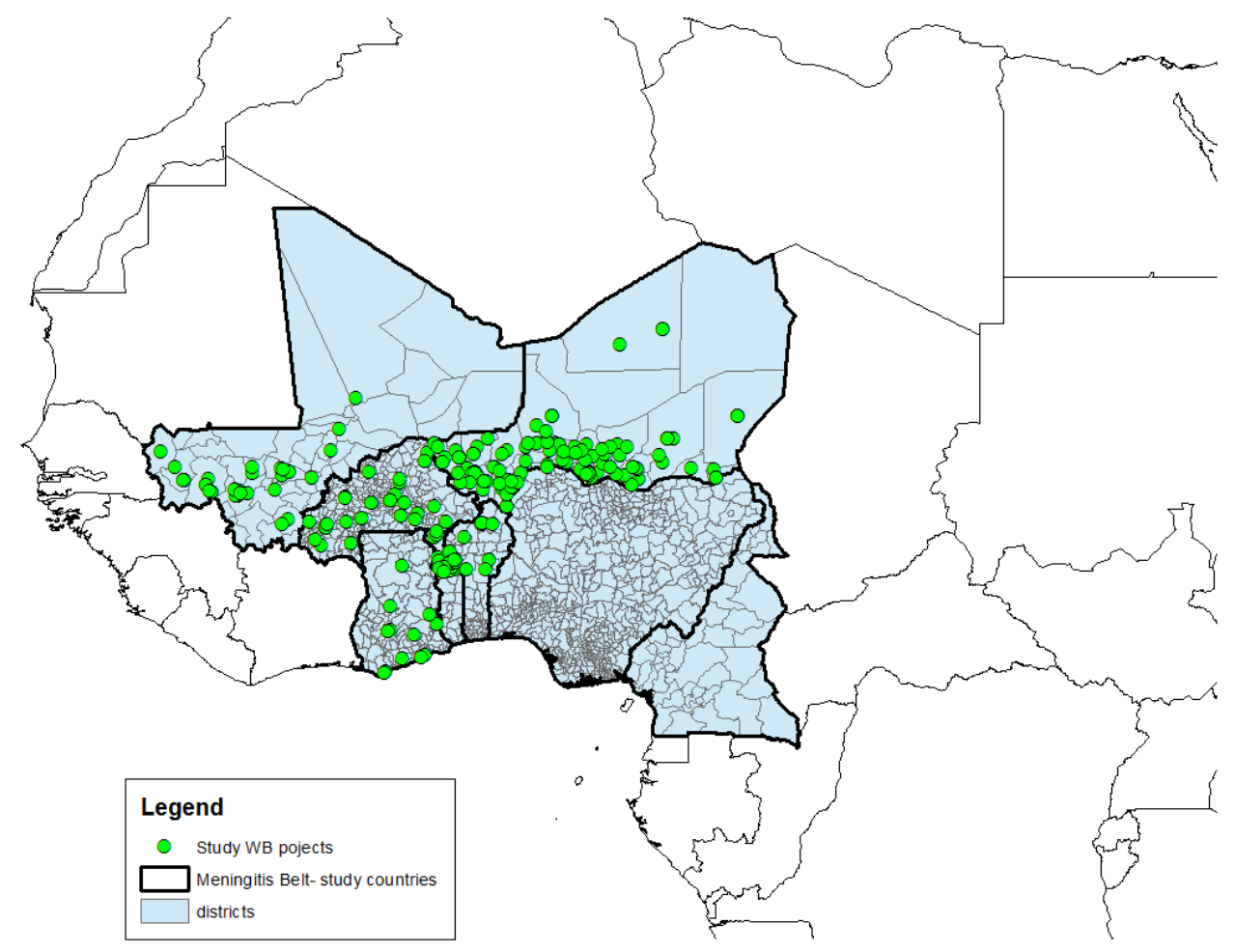

Figure 5: Locations of World Bank aid projects for countries and districts in study region over study years 

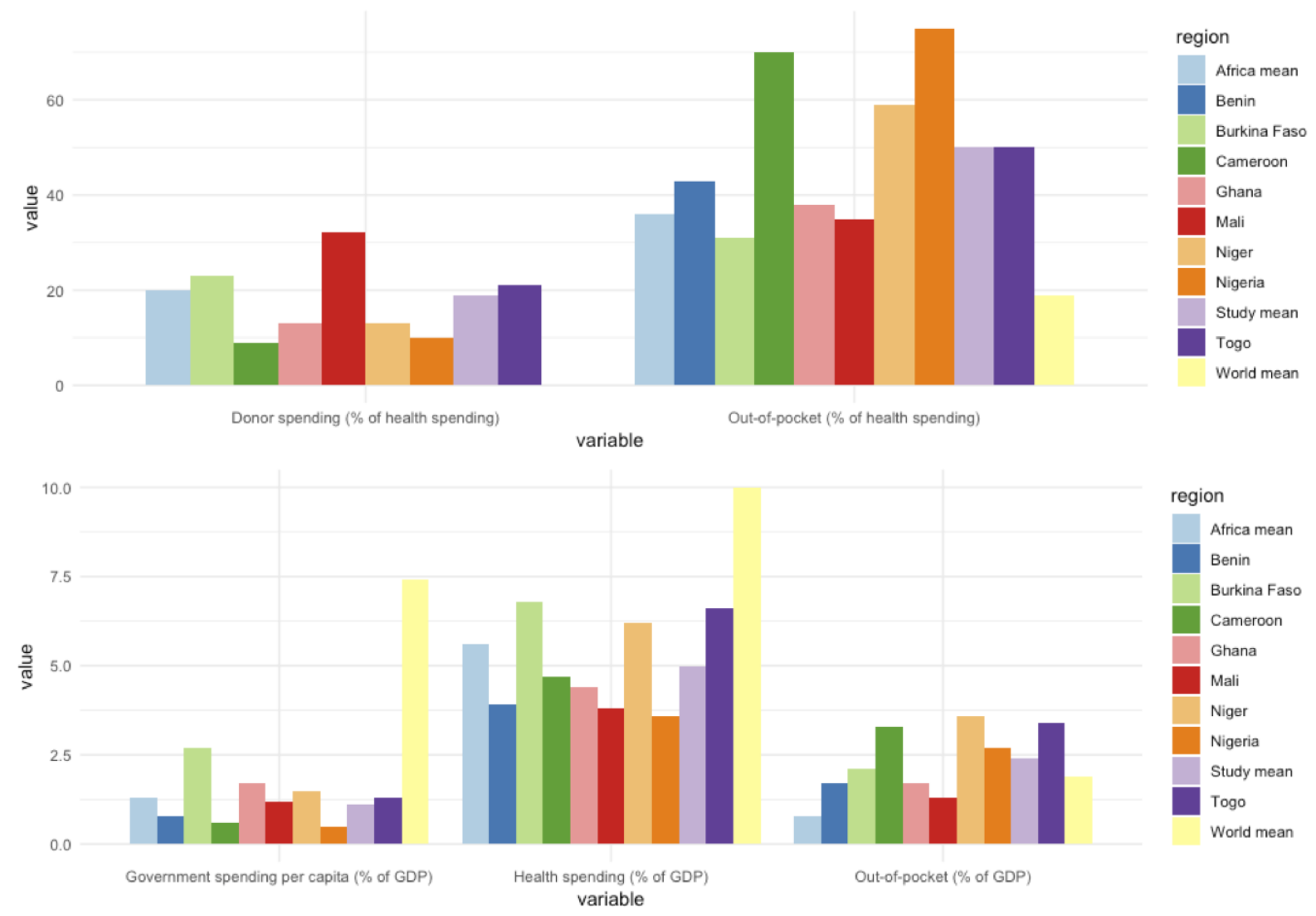

Figure 6: Health spending statistics across regions, 2016. Source: World Bank 

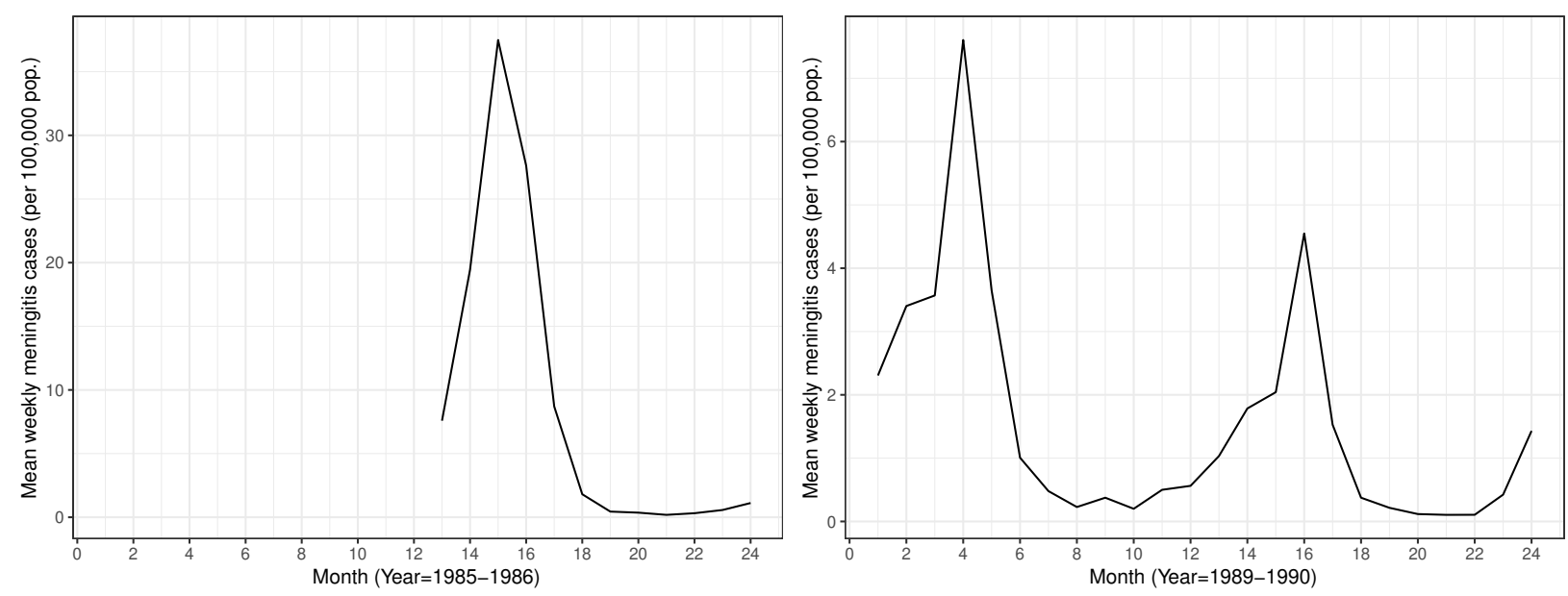

Figure 7: Meningitis Epidemic Curves (Niger)
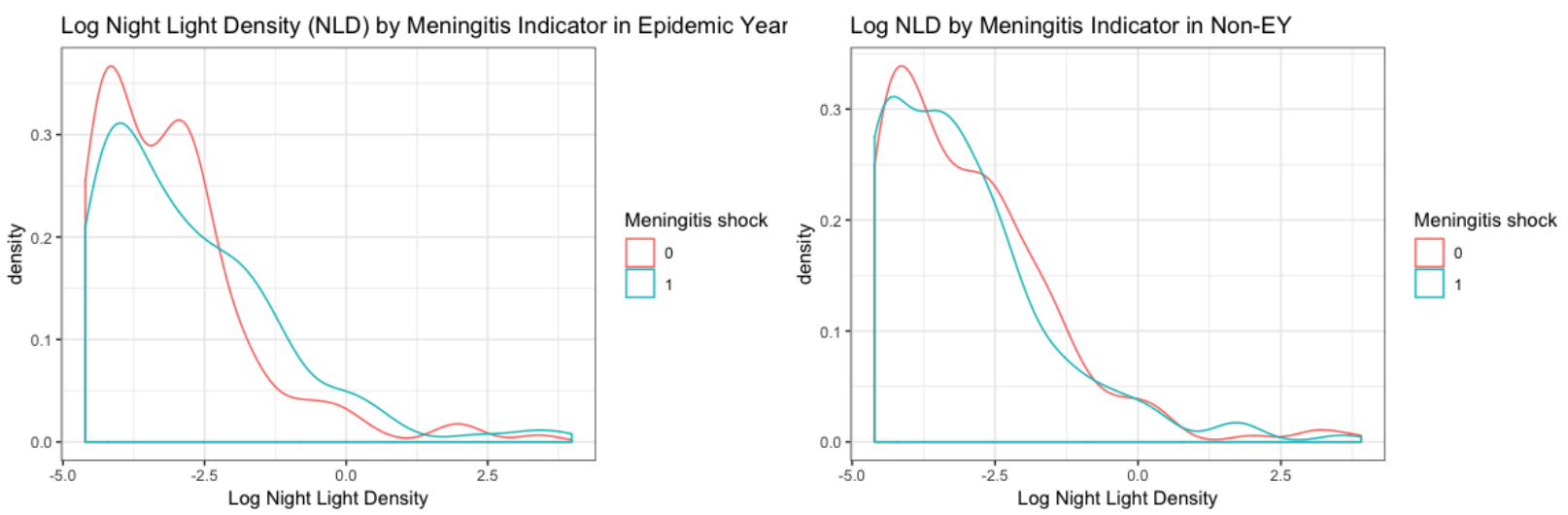

Figure 8: Stochastic dominance: Log night light density is higher in meningitis shock districts during declared epidemic year (EY). Lower in non-epidemic years 
Table 1: Summary Statistics, Africa

\begin{tabular}{|c|c|c|c|c|c|}
\hline Statistic & $\mathrm{N}$ & Mean & St. Dev. & Min & $\operatorname{Max}$ \\
\hline & \multicolumn{5}{|c|}{ District Level Night Light Data } \\
\hline Meningitis Shock (Z) & 1,141 & 0.36 & 0.48 & 0.00 & 1.00 \\
\hline Meningitis Cases $(/ 100,000)$ & 1,220 & 6.35 & 13.34 & 0.00 & 145.19 \\
\hline Epidemic Year & 1,329 & 0.39 & 0.49 & 0 & 1 \\
\hline Log Night Light Density & 1,329 & -2.74 & 1.71 & -4.61 & 3.98 \\
\hline Share Muslim & 1,302 & 0.75 & 0.36 & 0.00 & 1.00 \\
\hline Share Muslim x Hajj & 1,302 & 0.05 & 0.22 & 0.00 & 1.00 \\
\hline
\end{tabular}

DHS Child Level Data

\begin{tabular}{|c|c|c|c|c|c|}
\hline Infant Mortality & 16,486 & 0.38 & 0.49 & 0.00 & 1.00 \\
\hline WFA z & 17,401 & -1.54 & 1.33 & -5.99 & 5.72 \\
\hline HFA z & 17,401 & -1.47 & 1.63 & -6.00 & 5.89 \\
\hline Underweight & 17,401 & 0.38 & 0.48 & 0.00 & 1.00 \\
\hline Stunted & 17,401 & 0.36 & 0.48 & 0.00 & 1.00 \\
\hline $\mathrm{BCG}$ & 22,401 & 0.61 & 0.49 & 0.00 & 1.00 \\
\hline Nos. Polio & 22,422 & 1.45 & 1.31 & 0.00 & 3.00 \\
\hline Nos. DPT & 22,323 & 1.38 & 1.34 & 0.00 & 3.00 \\
\hline Measles & 21,979 & 0.42 & 0.49 & 0.00 & 1.00 \\
\hline Nos. Total Vacc. & 21,806 & 3.83 & 3.33 & 0.00 & 8.00 \\
\hline
\end{tabular}

World Bank Project Level Data

$\begin{array}{lcccrr}\text { Health Project } & 556 & 0.12 & 0.33 & 0 & 1 \\ \text { Comm. Total, USD } & 556 & 55,657,922 & 28,851,034 & 5,302,687 & 238,620,908 \\ \text { Comm. Health, USD } & 556 & 6,068,739 & 17,204,611 & 0 & 68,215,861 \\ \text { Comm. Non-Health, USD } & 556 & 49,589,183 & 33,754,342 & 0 & 238,620,908 \\ \text { Disb. Total, USD } & 547 & 47,585,463 & 26,440,235 & 1,987,862 & 310,653,294 \\ \text { Disb. Health, USD } & 547 & 5,503,057 & 15,818,254 & 0 & 61,602,090 \\ \text { Disb. Non-Health, USD } & 547 & 42,082,406 & 30,213,919 & 0 & 310,653,294 \\ \text { IEG Outcome } & 301 & 3.98 & 1.24 & 1.00 & 6.00\end{array}$

Niger District Ethnicity Data

578

0.38

0.49

0

1

Table 2: WHO recommended vaccination schedule

\begin{tabular}{lccc}
\hline \hline & Vaccine & Diseases & Age \\
\hline 1 & BCG & tuberculosis & at birth \\
2 & Polio $(\mathrm{OPV})$ & polio & at birth, $6,10,14$ weeks \\
3 & DPT & diphtheria, pertussis, tetanus & $6,10,14$ weeks \\
4 & Measles & measles & 9 months \\
\hline
\end{tabular}


Table 3: Balance on geographic and institutional characteristics

\begin{tabular}{|c|c|c|c|c|c|c|}
\hline & \multicolumn{6}{|c|}{ Panel A: Geographic Characteristics } \\
\hline & $\begin{array}{c}\text { Malaria } \\
(1)\end{array}$ & $\begin{array}{l}\text { Land Suitability } \\
\qquad(2)\end{array}$ & $\begin{array}{l}\text { Elevation } \\
\qquad(3)\end{array}$ & $\begin{array}{l}\text { Access to Rivers } \\
\text { (4) }\end{array}$ & $\begin{array}{c}\text { Distance to Sea Coast } \\
(5)\end{array}$ & $\begin{array}{c}\text { Distance to Capital } \\
(6)\end{array}$ \\
\hline Meningitis shock average & $\begin{array}{c}-1.680 \\
(3.214)\end{array}$ & $\begin{array}{c}-0.007 \\
(0.081)\end{array}$ & $\begin{array}{l}18.696 \\
(51.375)\end{array}$ & $\begin{array}{r}-0.077 \\
(0.339)\end{array}$ & $\begin{array}{l}-22.516 \\
(57.331)\end{array}$ & $\begin{array}{l}-19.465 \\
(131.928)\end{array}$ \\
\hline $\begin{array}{l}\text { Mean of outcome } \\
\text { Observations } \\
\mathrm{R}^{2} \\
\text { Country FE }\end{array}$ & $\begin{array}{l}22.204 \\
242 \\
0.576 \\
\text { Yes }\end{array}$ & $\begin{array}{l}0.325 \\
239 \\
0.503 \\
\text { Yes }\end{array}$ & $\begin{array}{l}374.821 \\
242 \\
0.554 \\
\text { Yes }\end{array}$ & $\begin{array}{l}0.467 \\
242 \\
0.094 \\
\text { Yes }\end{array}$ & $\begin{array}{l}128.404 \\
242 \\
0.322 \\
\text { Yes }\end{array}$ & $\begin{array}{l}404.695 \\
242 \\
0.250 \\
\text { Yes }\end{array}$ \\
\hline \multirow{2}{*}{ Country FE } & \multicolumn{6}{|c|}{ Panel B: Geographic and Institutional Characteristics } \\
\hline & $\begin{array}{l}\text { Share Muslim } \\
\text { (1) } \\
\end{array}$ & $\begin{array}{c}\text { Pastoral } \\
(2) \\
\end{array}$ & $\begin{array}{l}\text { Centralization Index } \\
\qquad(3) \\
\end{array}$ & $\begin{array}{l}\text { Centralization Dummy } \\
\qquad(4)\end{array}$ & $\begin{array}{l}\text { Diamond } \\
(5) \\
\end{array}$ & $\begin{array}{c}\text { Petrol } \\
(6)\end{array}$ \\
\hline Meningitis shock average & $\begin{array}{c}-0.218 \\
(0.149)\end{array}$ & $\begin{array}{c}-0.025 \\
(0.052)\end{array}$ & $\begin{array}{c}-1.182 \\
(0.867)\end{array}$ & $\begin{array}{c}-0.419 \\
(0.437)\end{array}$ & $\begin{array}{c}0.009 \\
(0.100)\end{array}$ & $\begin{array}{c}0.002 \\
(0.007)\end{array}$ \\
\hline Mean of outcome & 0.688 & 0.026 & 1.288 & 0.721 & 0.012 & 0.004 \\
\hline Observations & 236 & 764 & 768 & 768 & 242 & 242 \\
\hline $\mathrm{R}^{2}$ & 0.536 & 0.191 & 0.078 & 0.055 & 0.092 & 0.025 \\
\hline Country FE & Yes & Yes & Yes & Yes & Yes & Yes \\
\hline
\end{tabular}




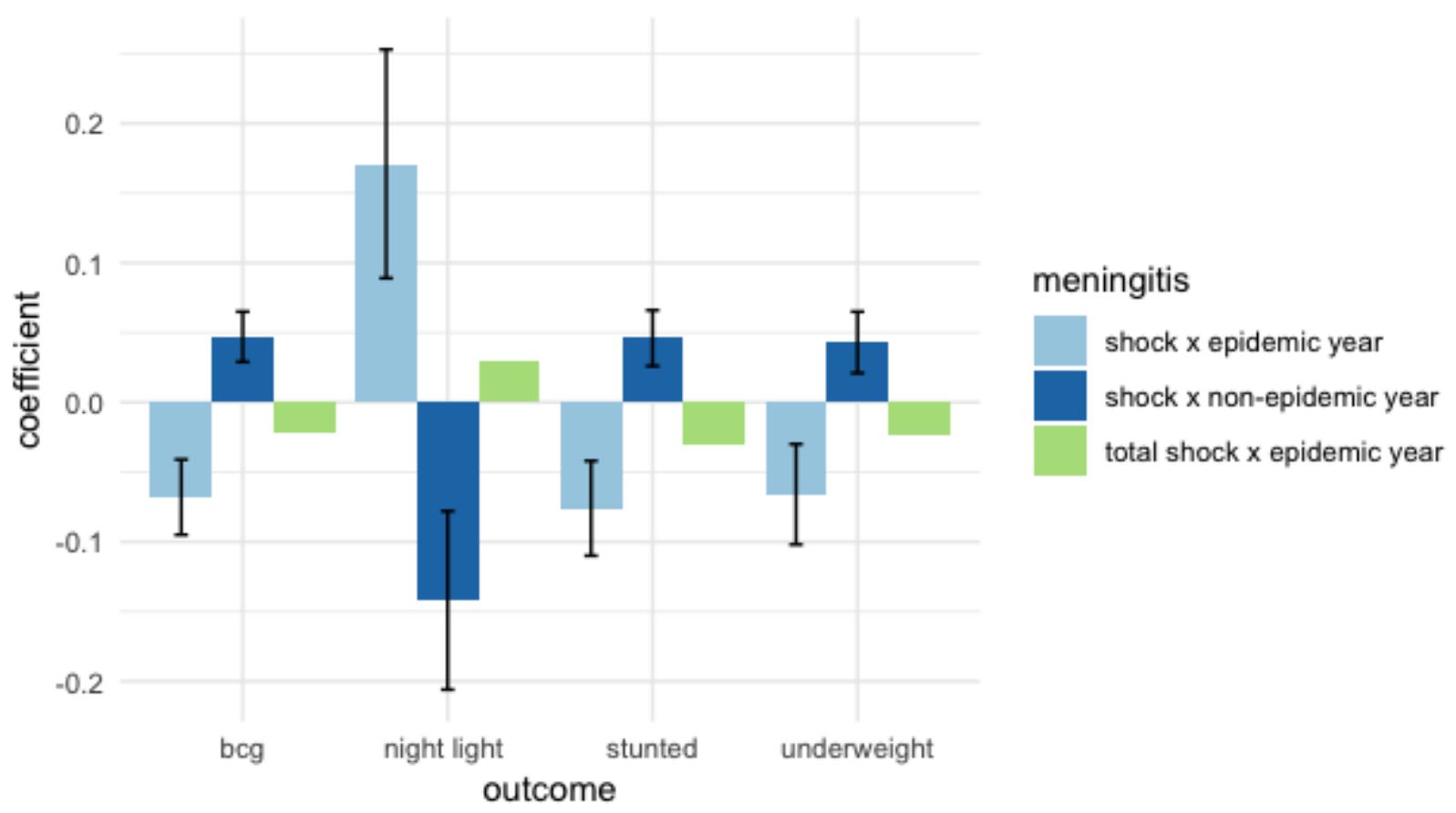

Figure 9: More economic activity, Less stunting and underweight children currently, if born in high meningitis shock districts but year was declared an epidemic year. In high shock, non epidemic year districts, lowered economic activity, and more stunting and underweight. Potential crowd-out of routine vaccines during epidemic years 
Table 4: Effect of meningitis shock on economic activity in epidemic vs non-epidemic years

\begin{tabular}{lcccc}
\hline \hline & & \multicolumn{3}{c}{ Log Night Light Density } \\
& $(1)$ & $(2)$ & $(3)$ & $(4)$ \\
\hline Meningitis shock & $-0.065^{*}$ & $-0.065^{*}$ & $-0.142^{* *}$ & $-0.142^{* *}$ \\
& $(0.036)$ & $(0.036)$ & $(0.064)$ & $(0.064)$ \\
Epidemic year & & $-0.827^{* * *}$ & $-0.916^{* * *}$ & 0.158 \\
& & $(0.081)$ & $(0.083)$ & $(0.098)$ \\
Meningitis shock & & & $0.171^{* *}$ & $0.171^{* *}$ \\
x Epidemic year & & & $(0.082)$ & $(0.082)$ \\
& & & -2.741 & -2.741 \\
Mean of outcome & -2.741 & -2.741 & Yes & Yes \\
District FE & Yes & Yes & Yes & No \\
Country x year FE & Yes & Yes & No & \\
Linear time trends & No & No & 1,141 & 1,141 \\
Observations & & & & \\
\hline \hline
\end{tabular}

Notes: Regressions estimated by OLS. Robust standard errors in parentheses clustered by district. Dependent variables are log night light density described in text from 8 African countries from 1992 to 2008. Meningitis shock is Z score indicator based on district level mean as described in text. Linear time trends are country specific time trends. ${ }^{* * *}$ Significant at the 1 percent level, ${ }^{* *}$ Significant at the 5 percent level, ${ }^{*}$ Significant at the 10 percent level. 
Table 5: Effect of meningitis shock on child current weight and height outcomes in epidemic vs non-epidemic years

\begin{tabular}{|c|c|c|c|c|c|c|c|c|}
\hline & \multicolumn{2}{|c|}{ WFA z } & \multicolumn{2}{|c|}{ Underweight } & \multicolumn{2}{|c|}{ HFA z } & \multicolumn{2}{|c|}{ Stunted } \\
\hline & $(1)$ & $(2)$ & (3) & $(4)$ & (5) & (6) & (7) & $(8)$ \\
\hline Meningitis shock & $\begin{array}{c}-0.176^{* *} \\
(0.081)\end{array}$ & $\begin{array}{c}-0.175^{* *} \\
(0.081)\end{array}$ & $\begin{array}{r}0.043^{*} \\
(0.022)\end{array}$ & $\begin{array}{r}0.042^{*} \\
(0.022)\end{array}$ & $\begin{array}{c}-0.178^{* *} \\
(0.079)\end{array}$ & $\begin{array}{c}-0.174^{* *} \\
(0.079)\end{array}$ & $\begin{array}{l}0.046^{* *} \\
(0.020)\end{array}$ & $\begin{array}{l}0.045^{* *} \\
(0.020)\end{array}$ \\
\hline Epidemic year & $\begin{array}{c}-0.217^{* *} \\
(0.101)\end{array}$ & $\begin{array}{c}-0.213^{* *} \\
(0.101)\end{array}$ & $\begin{array}{r}0.061^{*} \\
(0.036)\end{array}$ & $\begin{array}{c}0.059 \\
(0.036)\end{array}$ & $\begin{array}{c}-0.543^{* * *} \\
(0.126)\end{array}$ & $\begin{array}{c}-0.534^{* * *} \\
(0.128)\end{array}$ & $\begin{array}{l}0.157^{* * *} \\
(0.037)\end{array}$ & $\begin{array}{l}0.155^{* * *} \\
(0.037)\end{array}$ \\
\hline $\begin{array}{l}\text { Meningitis shock } \\
\text { x Epidemic year }\end{array}$ & $\begin{array}{l}0.288^{* *} \\
(0.119)\end{array}$ & $\begin{array}{c}0.281^{* *} \\
(0.119)\end{array}$ & $\begin{array}{r}-0.066^{*} \\
(0.036)\end{array}$ & $\begin{array}{r}-0.064^{*} \\
(0.036)\end{array}$ & $\begin{array}{l}0.301^{* * *} \\
(0.114)\end{array}$ & $\begin{array}{l}0.288^{* *} \\
(0.114)\end{array}$ & $\begin{array}{c}-0.076^{* *} \\
(0.034)\end{array}$ & $\begin{array}{c}-0.073^{* *} \\
(0.034)\end{array}$ \\
\hline Mean of outcome & -1.583 & -1.583 & 0.388 & 0.388 & -1.476 & -1.476 & 0.362 & 0.362 \\
\hline Mother's controls & Yes & Yes & Yes & Yes & Yes & Yes & Yes & Yes \\
\hline District FE & Yes & Yes & Yes & Yes & Yes & Yes & Yes & Yes \\
\hline Year of birth FE & Yes & Yes & Yes & Yes & Yes & Yes & Yes & Yes \\
\hline Country x year FE & Yes & No & Yes & No & Yes & No & Yes & No \\
\hline Linear time trends & No & Yes & No & Yes & No & Yes & No & Yes \\
\hline Observations & 15,032 & 15,032 & 15,032 & 15,032 & 15,032 & 15,032 & 15,032 & 15,032 \\
\hline
\end{tabular}

Notes: Regressions estimated by OLS. Robust standard errors in parentheses clustered by district. Dependent variables are child outcomes described in text from 8 African countries Mother's controls include mother's age at birth and level of education. Meningitis shock is Z score indicator based on district level mean as described in text. Linear time trends are country specific time trends. ${ }^{* * *}$ Significant at the 1 percent level, ${ }^{* *}$ Significant at the 5 percent level, ${ }^{*}$ Significant at the 10 percent level. 
Table 6: Effect of meningitis shock on at birth (bcg, polio) vs non-at birth recommended (dpt, measles) child vaccinations

\begin{tabular}{|c|c|c|c|c|c|c|c|c|}
\hline & \multicolumn{2}{|c|}{ BCG } & \multicolumn{2}{|c|}{ Nos. Polio } & \multicolumn{2}{|c|}{ DPT } & \multicolumn{2}{|c|}{ Measles } \\
\hline & $(1)$ & $(2)$ & (3) & $(4)$ & (5) & (6) & (7) & $(8)$ \\
\hline Meningitis shock & $\begin{array}{l}0.047^{* *} \\
(0.018)\end{array}$ & $\begin{array}{l}0.047^{* *} \\
(0.018)\end{array}$ & $\begin{array}{l}0.120^{* *} \\
(0.060)\end{array}$ & $\begin{array}{c}0.118^{*} \\
(0.060)\end{array}$ & $\begin{array}{r}0.118^{*} \\
(0.061)\end{array}$ & $\begin{array}{r}0.117^{*} \\
(0.061)\end{array}$ & $\begin{array}{l}0.014 \\
(0.037)\end{array}$ & $\begin{array}{c}0.013 \\
(0.037)\end{array}$ \\
\hline Epidemic year & $\begin{array}{l}0.048^{* *} \\
(0.022)\end{array}$ & $\begin{array}{c}0.047^{* *} \\
(0.022)\end{array}$ & $\begin{array}{l}0.164^{* *} \\
(0.075)\end{array}$ & $\begin{array}{l}0.161^{* *} \\
(0.076)\end{array}$ & $\begin{array}{l}0.145 \\
(0.091)\end{array}$ & $\begin{array}{c}0.142 \\
(0.091)\end{array}$ & $\begin{array}{l}0.113^{* * *} \\
(0.041)\end{array}$ & $\begin{array}{l}0.112^{* * *} \\
(0.041)\end{array}$ \\
\hline $\begin{array}{l}\text { Meningitis shock } \\
\text { x Epidemic year }\end{array}$ & $\begin{array}{c}-0.068^{* *} \\
(0.027)\end{array}$ & $\begin{array}{c}-0.068^{* *} \\
(0.027)\end{array}$ & $\begin{array}{c}-0.198^{* *} \\
(0.094)\end{array}$ & $\begin{array}{c}-0.194^{* *} \\
(0.094)\end{array}$ & $\begin{array}{c}-0.167 \\
(0.103)\end{array}$ & $\begin{array}{c}-0.162 \\
(0.104)\end{array}$ & $\begin{array}{c}-0.024 \\
(0.052))\end{array}$ & $\begin{array}{c}-0.024 \\
(0.052)\end{array}$ \\
\hline Mean of outcome & 0.591 & 0.591 & 1.375 & 1.375 & 1.328 & 1.328 & 0.406 & 0.406 \\
\hline Mother's controls & Yes & Yes & Yes & Yes & Yes & Yes & Yes & Yes \\
\hline District FE & Yes & Yes & Yes & Yes & Yes & Yes & Yes & Yes \\
\hline Year of birth FE & Yes & Yes & Yes & Yes & Yes & Yes & Yes & Yes \\
\hline Country x year FE & Yes & No & Yes & No & Yes & No & Yes & No \\
\hline Linear time trends & No & Yes & No & Yes & No & Yes & No & Yes \\
\hline Observations & 19,581 & 19,581 & 19,606 & 19,606 & 19,548 & 19,548 & 19,258 & 19,258 \\
\hline
\end{tabular}

Notes: Regressions estimated by OLS. Robust standard errors in parentheses clustered by district. Dependent variables are child outcomes described in text from 8 African countries. Mother's controls include mother's age at birth and level of education. Meningitis shock is Z score indicator based on district level mean as described in text. Linear time trends are country specific time trends. ${ }^{* * *}$ Significant at the 1 percent level, ${ }^{* *}$ Significant at the 5 percent level, ${ }^{*}$ Significant at the 10 percent level. 
Table 7: Effect of meningitis shock on infant mortality and number of total child vaccinations in epidemic vs non-epidemic years

\begin{tabular}{lcccc}
\hline \hline & \multicolumn{2}{c}{ Infant Mortality } & \multicolumn{2}{c}{ Total Vaccinations } \\
& $(1)$ & $(2)$ & $(3)$ & $(4)$ \\
\hline Meningitis shock & -0.009 & -0.009 & $0.309^{*}$ & $0.306^{*}$ \\
& $(0.018)$ & $(0.019)$ & $(0.166)$ & $(0.166)$ \\
Epidemic year & $-0.055^{* * *}$ & $-0.057^{* * *}$ & $0.461^{* *}$ & $0.453^{* *}$ \\
& $(0.019)$ & $(0.020)$ & $(0.216)$ & $(0.217)$ \\
Meningitis shock & & & & $-0.443^{*}$ \\
x Epidemic year & 0.009 & 0.009 & $-0.454^{*}$ & $(0.262)$ \\
& $(0.021)$ & $(0.021)$ & $(0.261)$ & 3.674 \\
Mean of outcome & 0.374 & 0.374 & 3.674 & Yes \\
Mother's controls & Yes & Yes & Yes & Yes \\
District FE & Yes & Yes & Yes & No \\
Year of birth FE & Yes & Yes & Yes & Yes \\
Country x year FE & Yes & No & Yes & No \\
Linear time trends & No & Yes & & 19,151 \\
\hline Observations & 15,141 & 15,141 & 19,151 & \\
\hline \hline
\end{tabular}

Notes: Regressions estimated by OLS. Robust standard errors in parentheses clustered by district. Dependent variables are child outcomes described in text from 8 African countries. Mother's controls include mother's age at birth and level of education. Meningitis shock is $\mathrm{Z}$ score indicator based on district level mean as described in text. Linear time trends are country specific time trends. ${ }^{* * *}$ Significant at the 1 percent level, ${ }^{* *}$ Significant at the 5 percent level, ${ }^{*}$ Significant at the 10 percent level. 
Table 8: First and second-stage estimates for interacted Share Muslim x Hajj instrument and comparisons with OLS results for night light density

\begin{tabular}{lcccc}
\hline \hline & & \multicolumn{3}{c}{ Panel A: First-Stage Estimates } \\
& & \multicolumn{3}{c}{ Meningitis Shock } \\
& $(1)$ & $(2)$ & $(3)$ & $(4)$ \\
\hline Share Muslim x Hajj & $-15.314^{* * *}$ & $-15.314^{* * *}$ & $-17.225^{* * *}$ & $-17.225^{* * *}$ \\
& $(2.910)$ & $(2.910)$ & $(2.902)$ & $(2.902)$ \\
& & & & \\
Epidemic year and Shock & No & No & Yes & Yes \\
x Year Interaction & Yes & Yes & Yes & Yes \\
District FE & Yes & No & Yes & No \\
Country x year FE & No & Yes & No & Yes \\
Linear time trends & & & & 35.23 \\
& 27.69 & 27.69 & 35.23 & \\
F-Stat of Excluded Instrument & & & & \\
& & & & \\
Observations & 1,114 & 1,114 & 1,114 & 1,114 \\
\hline
\end{tabular}

Panel B: Second-Stage 2SLS vs OLS Estimates

Log Night Light Density

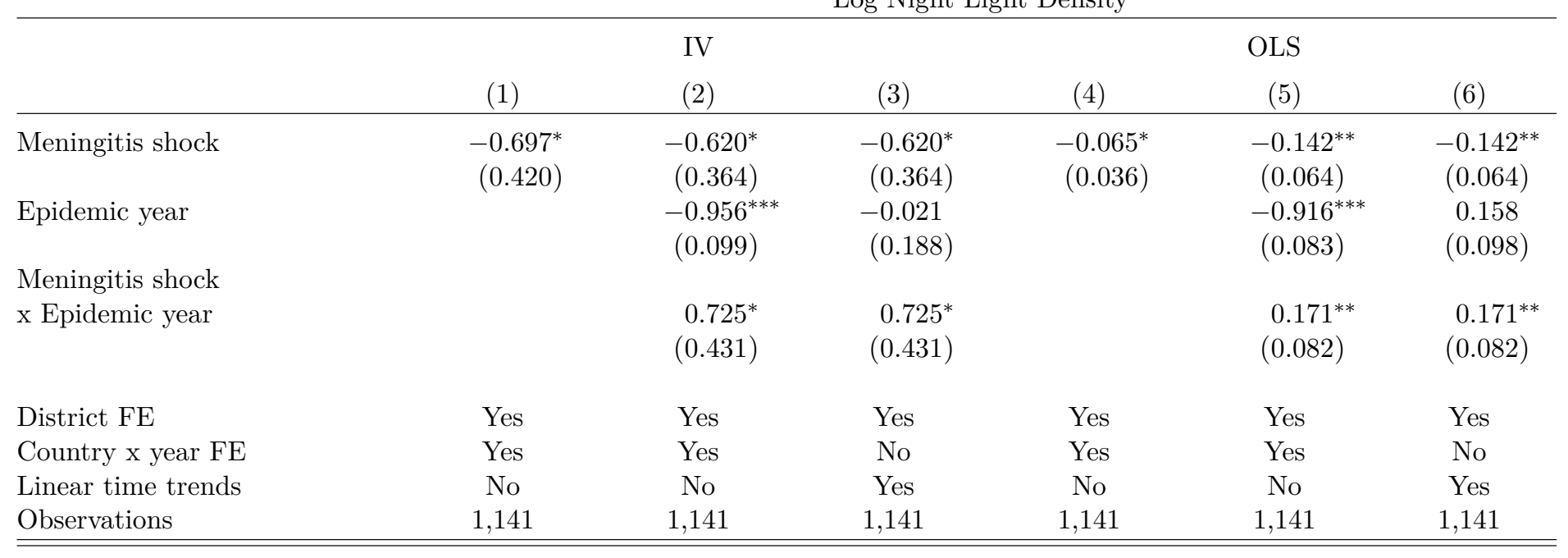

Notes: Robust standard errors in parentheses clustered by district in all specifications. Meningitis shock is Z score indicator based on district level mean as described in text. Log night light density outcomes described in text from 8 African countries from 1992 to 2008 . Linear time trends are country specific time trends. In Panel B, IV estimates from column (1) to (3) and OLS estimates from column (4) to (6). ${ }^{* * *}$ Significant at the 1 percent level, ${ }^{* *}$ Significant at the 5 percent level, * Bignificant at the 10 percent level. 


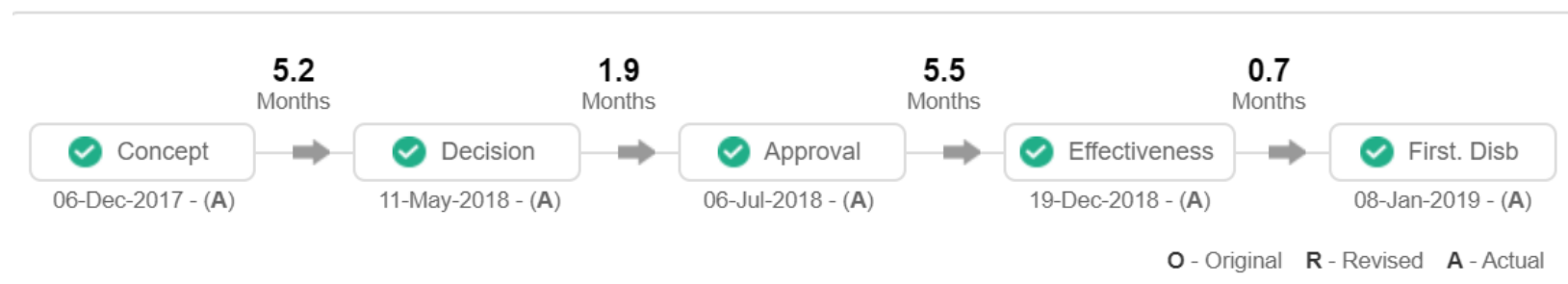

Figure 10: World Bank project approval example snapshot

Table 9: Effect of meningitis shock and epidemic year on share of World Bank aid health vs non-health projects approved

\begin{tabular}{lcccc}
\hline \hline & & & Health Project \\
& $(1)$ & $(2)$ & $(3)$ & $(4)$ \\
\hline Meningitis shock & & 0.141 & -0.039 & -0.005 \\
& & $(0.134)$ & $(0.097)$ & $(0.133)$ \\
Epidemic year & $0.824^{* * *}$ & & $0.841^{* * *}$ & $0.910^{* * *}$ \\
& $(0.093)$ & & $(0.090)$ & $(0.068)$ \\
Meningitis shock & & & -0.121 \\
x Epidemic year & & & & $(0.141)$ \\
& & & 0.164 & 0.164 \\
Mean of outcome & 0.126 & 0.164 & Yes & No \\
District FE & Yes & Yes & No & Yes \\
Country x year FE & No & No & Yes & \\
Linear time trends & Yes & Yes & & 213 \\
Observations & & & 213 & Des \\
\hline \hline
\end{tabular}

Notes: Regressions estimated by OLS. Robust standard errors in parentheses clustered by district. Dependent variable is indicator for whether or not project is classified as a health project as described in text from study countries. There are not enough observations to include a full range of country x year FE across all models. Results remain mostly unchanged when separate district and year FE are included. Meningitis shock is Z score indicator based on district level mean as described in text. Linear time trends are country specific time trends. ${ }^{* * *}$ Significant at the 1 percent level, ${ }^{* *}$ Significant at the 5 percent level, ${ }^{*}$ Significant at the 10 percent level. 
Table 10: Effect of meningitis shock and epidemic year on amount committed and disbursed to World Bank aid projects

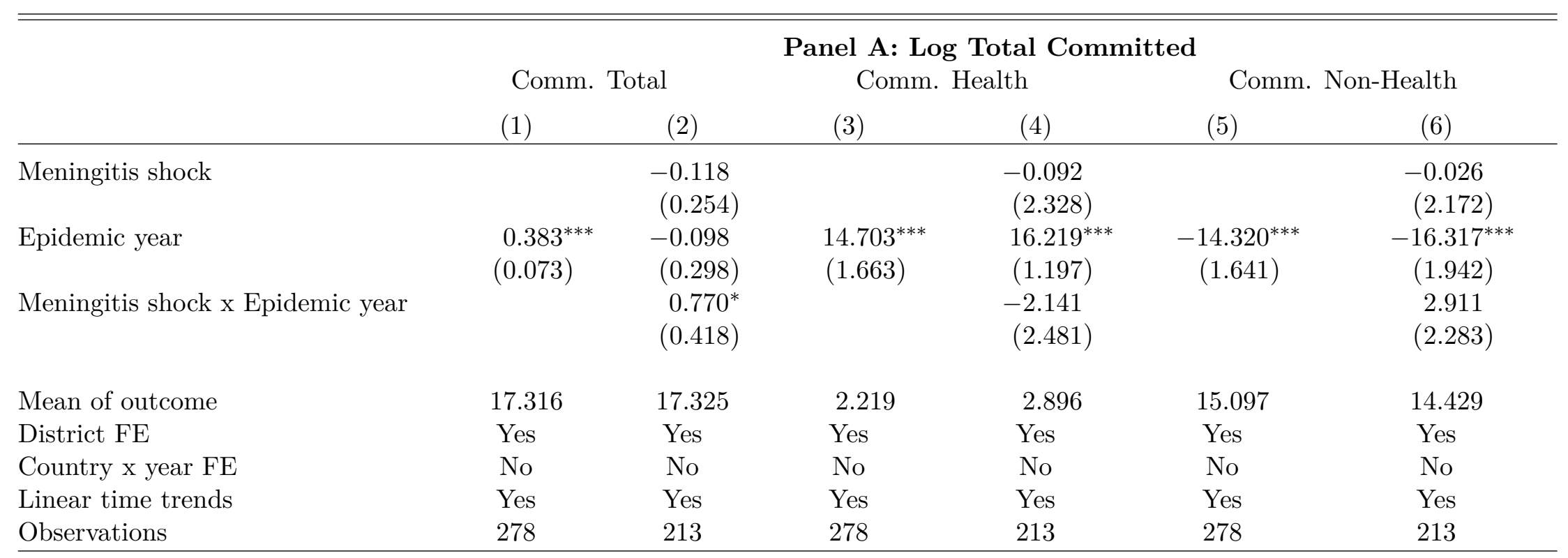

Disb. Total

Panel B: Log Total Disbursed

$(1)$

$(2)$

Disb. Health

Disb. Non-Health

\begin{tabular}{|c|c|c|c|c|c|c|}
\hline & $(1)$ & $(2)$ & $(3)$ & $(4)$ & $(5)$ & $(6)$ \\
\hline Meningitis shock & & $\begin{array}{c}0.224 \\
(0.140)\end{array}$ & & $\begin{array}{c}0.295 \\
(2.449)\end{array}$ & & $\begin{array}{c}-0.071 \\
(2.475)\end{array}$ \\
\hline Epidemic year & $\begin{array}{c}0.268^{* *} \\
(0.109)\end{array}$ & $\begin{array}{r}-0.145 \\
(0.328)\end{array}$ & $\begin{array}{l}14.809^{* * *} \\
(1.665)\end{array}$ & $\begin{array}{l}16.454^{* * *} \\
(1.213)\end{array}$ & $\begin{array}{c}-14.541^{* * *} \\
(1.626)\end{array}$ & $\begin{array}{c}-16.600^{* * *} \\
(1.093)\end{array}$ \\
\hline Meningitis shock x Epidemic year & & $\begin{array}{c}0.463 \\
(0.413)\end{array}$ & & $\begin{array}{c}-2.563 \\
(2.598)\end{array}$ & & $\begin{array}{c}3.026 \\
(2.548)\end{array}$ \\
\hline Mean of outcome & 17.175 & 17.241 & 2.302 & 3.035 & 14.873 & 14.206 \\
\hline District FE & Yes & Yes & Yes & Yes & Yes & Yes \\
\hline Country $\mathrm{x}$ year FE & No & No & No & No & No & No \\
\hline Linear time trends & Yes & Yes & Yes & Yes & Yes & Yes \\
\hline Observations & 269 & 204 & 269 & 204 & 269 & 204 \\
\hline
\end{tabular}

Notes: Regressions estimated by OLS. Robust standard errors in parentheses clustered by district. Dependent variables are log (1+ committed or disbursed amounts) for health and non-health projects and for total projects as described in text from study countries. There are not enough observations to include a full range of country $\mathrm{x}$ year FE across all models. Results remain mostly unchanged when separate district and year FE are included. Meningitis shock is $\mathrm{Z}$ score indicator based on district level mean as defined in text. Linear time trends are country level time trends. ${ }^{* * *}$ Significant at the 1 percent level, ${ }^{* *}$ Significant at the 5 percent level, ${ }^{*}$ Significant at the 10 percent level. 
Table 11: Effect of meningitis shock and epidemic year on independent rating of World Bank aid projects

\section{IEG Outcome}

(1)

(2)

(3)

(4)

Meningitis shock

Epidemic year

Meningitis shock x Epidemic year

$\begin{array}{cc}-2.247^{* * *} & 1.108^{* * *} \\ (0.313) & (0.350) \\ & \\ & -0.344^{* * *} \\ & (0.098) \\ & -3.239^{* * *} \\ & (0.424)\end{array}$

Health project

Epidemic year x Health project
$-1.341^{* * *}$

$(0.234)$
Mean of outcome

District FE

Country x year FE

Linear time trends

Observations

\begin{tabular}{llll}
3.977 & 3.977 & 3.977 & 4.029 \\
Yes & Yes & Yes & Yes \\
No & No & No & No \\
Yes & Yes & Yes & Yes \\
301 & 301 & 301 & 204 \\
\hline
\end{tabular}

0.307

(0.466)

$-2.386^{* * *}$

(0.390)

0.032

(0.512)

$(0.098)$

$-3.239^{* * *}$$$
\text { (0.424) }
$$

Notes: Regressions estimated by OLS. Robust standard errors in parentheses clustered by district. Dependent variables are World Bank project independent evaluation group (IEG) ratings outcomes described in text from study countries. There are not enough observations to include a full range of country x year FE across all models. Results remain mostly unchanged when separate district and year FE are included. Meningitis shock is Z score indicator based on district level mean as described in text. ${ }^{* *}$ Significant at the 1 percent level, ${ }^{* *}$ Significant at the 5 percent level, ${ }^{*}$ Significant at the 10 percent level. 
Table 12: Effect of meningitis shock on night light density outcomes by World Bank aid share of health projects, and total committed and disbursed aid

\begin{tabular}{|c|c|c|c|c|c|}
\hline & \multicolumn{5}{|c|}{ Log Night Light Density } \\
\hline & $(1)$ & $(2)$ & $(3)$ & $(4)$ & $(5)$ \\
\hline Meningitis shock & $\begin{array}{r}-0.094^{*} \\
(0.058)\end{array}$ & $\begin{array}{r}-0.103^{*} \\
(0.061)\end{array}$ & $\begin{array}{r}-0.103^{*} \\
(0.061)\end{array}$ & $\begin{array}{c}0.767 \\
(1.578)\end{array}$ & $\begin{array}{r}-0.153 \\
(0.310)\end{array}$ \\
\hline Share health & $\begin{array}{c}0.055 \\
(0.222)\end{array}$ & & & & \\
\hline Comm. health & & $\begin{array}{c}-0.130 \\
(0.117)\end{array}$ & & & \\
\hline Disb. health & & & $\begin{array}{c}-0.131 \\
(0.117)\end{array}$ & & \\
\hline Comm. total & & & & $\begin{array}{c}-0.033 \\
(0.137)\end{array}$ & \\
\hline Disb. total & & & & & $\begin{array}{c}0.005 \\
(0.133)\end{array}$ \\
\hline Meningitis shock x Share health & $\begin{array}{c}0.188^{*} \\
(0.095)\end{array}$ & & & & \\
\hline Meningitis shock x Comm. health & & $\begin{array}{c}0.009^{*} \\
(0.005)\end{array}$ & & & \\
\hline Meningitis shock x Disb. health & & & $\begin{array}{c}0.009^{*} \\
(0.005)\end{array}$ & & \\
\hline Meningitis shock x Comm. total & & & & $\begin{array}{r}-0.045 \\
(0.089)\end{array}$ & \\
\hline Meningitis shock x Disb. total & & & & & $\begin{array}{c}0.007 \\
(0.018)\end{array}$ \\
\hline Mean of outcome & -3.056 & -3.056 & -3.056 & -3.056 & -3.056 \\
\hline District FE & Yes & Yes & Yes & Yes & Yes \\
\hline Country x year FE & Yes & Yes & Yes & Yes & Yes \\
\hline Linear time trends & No & No & No & No & No \\
\hline Observations & 147 & 147 & 147 & 147 & 147 \\
\hline
\end{tabular}

Notes: Regressions estimated by OLS. Robust standard errors in parentheses clustered by district. Dependent variable is Log night light density described in text from 8 African countries. Meningitis shock is Z score indicator based on district level mean as described in text. Results remain unchanged with linear, country specific time trends. ${ }^{* *}$ Significant at the 1 percent level, ${ }^{* *}$ Significant at the 5 percent level, ${ }^{*}$ Significant at the 10 percent level. 


\begin{tabular}{|c|c|c|}
\hline $\begin{array}{l}\text { Top } 5 \text { WB Project titles by Epidemic year } \\
\text { and Health classification }\end{array}$ & Health project $=0$ & Health project=1 \\
\hline Epidemic year $=0$ & $\begin{array}{l}\text { - Transport sector project } \\
\text { - Transport sector program support } \\
\text { project } \\
\text { - Urban infrastructure rehabilitation } \\
\text { project } \\
\text { - Transport infrastructure } \\
\text { rehabilitation project } \\
\text { - Local urban infrastructure } \\
\text { development project }\end{array}$ & $\begin{array}{ll}\text { - } & \text { Community action program } \\
\text { - } & \text { Social fund } \\
\text { - Health, fertility and nutrition } \\
\text { project }\end{array}$ \\
\hline Epidemic year=1 & $\begin{array}{l}\text { - } \text { Road Transport project } \\
\text { Pilot private irrigation promotion } \\
\text { - Post-Primary education } \\
\text { - Regional Hydropower development } \\
\text { project } \\
\text { - Village infrastructure project }\end{array}$ & $\begin{array}{l}\text { - Health sector development } \\
\text { program } \\
\text { - Economic recovery and adjustment } \\
\text { credit (ERAC) project }\end{array}$ \\
\hline
\end{tabular}

Figure 11: Top 5 World Bank health and non-health projects funded by project title in epidemic and non-epidemic years 
Table 13: Effect of meningitis shock on economic activity in epidemic vs non-epidemic years, co-ethnic vs non-co-ethnic with president districts, Niger

\begin{tabular}{|c|c|c|c|c|c|c|}
\hline & \multicolumn{6}{|c|}{ Log Night Light Density } \\
\hline & $(1)$ & $(2)$ & $(3)$ & $(4)$ & $(5)$ & $(6)$ \\
\hline Meningitis shock & $\begin{array}{r}-0.085^{*} \\
(0.046)\end{array}$ & $\begin{array}{r}-0.085^{*} \\
(0.049)\end{array}$ & $\begin{array}{c}-0.171^{* *} \\
(0.077)\end{array}$ & $\begin{array}{r}-0.085^{*} \\
(0.045)\end{array}$ & $\begin{array}{c}-0.127^{* *} \\
(0.057)\end{array}$ & $\begin{array}{c}-0.203^{* *} \\
(0.085)\end{array}$ \\
\hline Epidemic year & & $\begin{array}{l}0.567^{* * *} \\
(0.115)\end{array}$ & $\begin{array}{l}0.472^{* * *} \\
(0.087)\end{array}$ & & & $\begin{array}{l}0.471^{* * * *} \\
(0.086)\end{array}$ \\
\hline Same ethnicity & & & & $\begin{array}{c}0.001 \\
(0.037)\end{array}$ & $\begin{array}{c}-0.032 \\
(0.035)\end{array}$ & $\begin{array}{c}-0.033 \\
(0.037)\end{array}$ \\
\hline Meningitis shock x Epidemic year & & & $\begin{array}{c}0.230^{* *} \\
(0.091)\end{array}$ & & & $\begin{array}{c}0.221^{* *} \\
(0.085)\end{array}$ \\
\hline Meningitis shock x Same ethnicity & & & & & $\begin{array}{c}0.112^{* *} \\
(0.047)\end{array}$ & $\begin{array}{c}0.094^{*} \\
(0.048)\end{array}$ \\
\hline Mean of outcome & -3.224 & -3.224 & -3.224 & -3.224 & -3.224 & -3.224 \\
\hline District FE & Yes & Yes & Yes & Yes & Yes & Yes \\
\hline Year FE & Yes & Yes & Yes & Yes & Yes & Yes \\
\hline Observations & 578 & 578 & 578 & 578 & 578 & 578 \\
\hline
\end{tabular}

Notes: Regressions estimated by OLS. Robust standard errors in parentheses clustered by district. Dependent variable is log $(0.01+$ night light density) in Niger from 1992 to 2008 . Meningitis shock and epidemic year variables as defined in text. Same ethnicity is if district shares same ethnicity as president. ${ }^{* * *}$ Significant at the 1 percent level, ${ }^{* *}$ Significant at the 5 percent level, ${ }^{*}$ Significant at the 10 percent level. 
Table 14: Split sample: Effect of meningitis shock on economic activity in epidemic vs non-epidemic years, co-ethnic vs non-co-ethnic with president districts, Niger

\begin{tabular}{lcccc}
\hline \hline & \multicolumn{2}{c}{ Epidemic years } & \multicolumn{2}{c}{ Non-epidemic years } \\
& $(1)$ & $(2)$ & $(3)$ & $(4)$ \\
\hline Meningitis shock & 0.037 & -0.010 & $-0.170^{* *}$ & $-0.234^{* * *}$ \\
& $(0.041)$ & $(0.042)$ & $(0.069)$ & $(0.091)$ \\
Same ethnicity & -0.035 & $-0.085^{* *}$ & 0.038 & 0.009 \\
& $(0.033)$ & $(0.038)$ & $(0.056)$ & $(0.052)$ \\
Meningitis shock x Same ethnicity & & 0.100 & & $0.201^{* *}$ \\
& & $(0.065)$ & & $(0.082)$ \\
Mean of outcome & & & & -3.199 \\
District FE & -3.284 & -3.284 & -3.199 & Yes \\
Year FE & Yes & Yes & Yes & Yes \\
Observations & Yes & Yes & Yes & 408 \\
\hline \hline
\end{tabular}

Notes: Regressions estimated by OLS. Robust standard errors in parentheses clustered by district. Dependent variable is log $(0.01+$ night light density) in Niger from 1992 to 2008 . Meningitis shock and epidemic year variables as defined in text. Same ethnicity is if district shares same ethnicity as president. ${ }^{* * *}$ Significant at the 1 percent level, ${ }^{* *}$ Significant at the 5 percent level, ${ }^{*}$ Significant at the 10 percent level. 
Table 15: Split sample: Effect of meningitis shock on infant mortality and child current weight and height outcomes in epidemic vs. non-epidemic years, co-ethnic vs non co-ethnic with president districts, Niger

\begin{tabular}{|c|c|c|c|c|c|c|}
\hline & \multicolumn{3}{|c|}{ Epidemic years } & \multicolumn{3}{|c|}{ Non-Epidemic years } \\
\hline & (Mortality) & (Underweight) & (Stunted) & (Mortality) & (Underweight) & (Stunted) \\
\hline Meningitis shock & $\begin{array}{c}0.044 \\
(0.029)\end{array}$ & $\begin{array}{r}0.295^{*} \\
(0.169)\end{array}$ & $\begin{array}{l}0.302^{* * *} \\
(0.051)\end{array}$ & $\begin{array}{c}0.020 \\
(0.028)\end{array}$ & $\begin{array}{c}-0.014 \\
(0.029)\end{array}$ & $\begin{array}{c}-0.017 \\
(0.024)\end{array}$ \\
\hline Same ethnicity & $\begin{array}{c}-0.002 \\
(0.038)\end{array}$ & $\begin{array}{c}0.382^{* *} \\
(0.165)\end{array}$ & $\begin{array}{l}0.421^{* * *} \\
(0.047)\end{array}$ & $\begin{array}{c}0.019 \\
(0.040)\end{array}$ & $\begin{array}{c}-0.035 \\
(0.022)\end{array}$ & $\begin{array}{c}-0.037 \\
(0.023)\end{array}$ \\
\hline Meningitis shock x Same ethnicity & $\begin{array}{r}-0.078^{*} \\
(0.045)\end{array}$ & $\begin{array}{c}-0.372^{* *} \\
(0.174)\end{array}$ & $\begin{array}{c}-0.321^{* * *} \\
(0.061)\end{array}$ & $\begin{array}{c}-0.040 \\
(0.059)\end{array}$ & $\begin{array}{c}0.028 \\
(0.048)\end{array}$ & $\begin{array}{c}0.078 \\
(0.047)\end{array}$ \\
\hline Mean of outcome & 0.349 & 0.605 & 0.568 & 0.339 & 0.378 & 0.316 \\
\hline Mother's controls & Yes & Yes & Yes & Yes & Yes & Yes \\
\hline District FE & Yes & Yes & Yes & Yes & Yes & Yes \\
\hline Year of birth FE & Yes & Yes & Yes & Yes & Yes & Yes \\
\hline Year FE* & Yes & Yes & Yes & Yes & Yes & Yes \\
\hline Observations & 2,272 & 1,844 & 1,844 & 4,294 & 5,993 & 5,993 \\
\hline
\end{tabular}

Notes: Regressions estimated by OLS. Robust standard errors in parentheses clustered by district. Dependent variables are child outcomes as described in text from Niger. Meningitis shock is Z score indicator based on district level mean as described in text. Mother's controls include mother's age at birth and level of education. Year fixed effects are dropped for underweight and stunted outcomes in epidemic years due to not enough levels in the epidemic years. Results are unchanged for non-epidemic years if drop year fixed effects. ${ }^{* *}$ Significant at the 1 percent level, ${ }^{* *}$ Significant at the 5 percent level, ${ }^{*}$ Significant at the 10 percent level. 
Table 16: Split sample: Effect of meningitis shock on child vaccination outcomes in epidemic vs non-epidemic years, co-ethnic vs non co-ethnic with president districts, Niger

\begin{tabular}{|c|c|c|c|c|c|c|}
\hline & \multicolumn{3}{|c|}{ Epidemic years } & \multicolumn{3}{|c|}{ Non-Epidemic years } \\
\hline & (Nos. Polio) & $(\mathrm{DPT})$ & (Total) & (Nos. Polio) & $(\mathrm{DPT})$ & (Total) \\
\hline Meningitis shock & $\begin{array}{c}-0.202^{* *} \\
(0.077)\end{array}$ & $\begin{array}{c}-0.152 \\
(0.072)\end{array}$ & $\begin{array}{c}-0.301 \\
(0.331)\end{array}$ & $\begin{array}{c}0.086 \\
(0.082)\end{array}$ & $\begin{array}{c}0.091 \\
(0.083)\end{array}$ & $\begin{array}{c}0.178 \\
(0.186)\end{array}$ \\
\hline Same ethnicity & $\begin{array}{c}-0.961^{* * *} \\
(0.071)\end{array}$ & $\begin{array}{c}-1.148^{* * *} \\
(0.060)\end{array}$ & $\begin{array}{c}-2.309^{* * *} \\
(0.330)\end{array}$ & $\begin{array}{c}0.041 \\
(0.115)\end{array}$ & $\begin{array}{c}0.043 \\
(0.117)\end{array}$ & $\begin{array}{c}0.142 \\
(0.275)\end{array}$ \\
\hline Meningitis shock x Same ethnicity & $\begin{array}{c}0.185^{* *} \\
(0.088)\end{array}$ & $\begin{array}{c}0.143 \\
(0.104)\end{array}$ & $\begin{array}{c}0.233 \\
(0.330)\end{array}$ & $\begin{array}{c}-0.227 \\
(0.175)\end{array}$ & $\begin{array}{c}-0.202 \\
(0.173)\end{array}$ & $\begin{array}{c}-0.467 \\
(0.387)\end{array}$ \\
\hline Mean of outcome & 1.422 & 1.362 & 3.843 & 0.933 & 0.946 & 2.620 \\
\hline Mother's controls & Yes & Yes & Yes & Yes & Yes & Yes \\
\hline District FE & Yes & Yes & Yes & Yes & Yes & Yes \\
\hline Year of birth FE & Yes & Yes & Yes & Yes & Yes & Yes \\
\hline Year $\mathrm{FE}^{*}$ & Yes & Yes & Yes & Yes & Yes & Yes \\
\hline Observations & 2,059 & 2,049 & 2,016 & 8,870 & 8,865 & 8,825 \\
\hline
\end{tabular}

Notes: Regressions estimated by OLS. Robust standard errors in parentheses clustered by district. Dependent variables are child vaccination outcomes as described in text from Niger. Meningitis shock is Z score indicator based on district level mean as described in text. Mother's controls include mother's age at birth and level of education. Year fixed effects are dropped for vaccination outcomes in epidemic years due to not enough levels in the epidemic years. Results are unchanged for non-epidemic years if drop year fixed effects. ${ }^{* * *}$ Significant at the 1 percent level, ${ }^{* *}$ Significant at the 5 percent level, ${ }^{*}$ Significant at the 10 percent level. 


\section{References}

Acemoglu, Daron, and Simon Johnson. 2007. "Disease and development: the effect of life expectancy on economic growth." Journal of political Economy 115 (6): 925-985.

Adda, Jérôme. 2016. "Economic activity and the spread of viral diseases: Evidence from high frequency data." The Quarterly Journal of Economics 131 (2): 891-941.

Adhvaryu, Achyuta, James Fenske, and Anant Nyshadham. 2019. "Early life circumstance and adult mental health." Journal of Political Economy 127 (4): 1516-1549.

Adhvaryu, Achyuta, Prashant Bharadwaj, James Fenske, Anant Nyshadham, Richard Stanley et al. 2016. Dust and Death: Evidence from the West African Harmattan. Technical report Centre for the Study of African Economies, University of Oxford.

Ahmed, Qanta A, Yaseen M Arabi, and Ziad A Memish. 2006. "Health risks at the Hajj." The Lancet 367 (9515): 1008-1015.

Akweongo, Patricia, Maxwell A Dalaba, Mary H Hayden, Timothy Awine, Gertrude N Nyaaba, Dominic Anaseba, Abraham Hodgson, Abdulai A Forgor, and Rajul Pandya. 2013. "The economic burden of meningitis to households in Kassena-Nankana district of Northern Ghana." PloS one 8 (11).

Aldashev, Gani, Marco Marini, and Thierry Verdier. 2019. "Samaritan Bundles: Fundraising Competition and Inefficient Clustering in NGO Projects." The Economic Journal .

Alesina, Alberto, and David Dollar. 2000. "Who gives foreign aid to whom and why?" Journal of economic growth 5 (1): 33-63.

Alesina, Alberto, Reza Baqir, and William Easterly. 1999. "Public goods and ethnic divisions." The Quarterly journal of economics 114 (4): 1243-1284. 
Alesina, Alberto, Stelios Michalopoulos, and Elias Papaioannou. 2016. "Ethnic inequality." Journal of Political Economy 124 (2): 428-488.

Algarni, Homoud, Ziad A Memish, and Abdullah M Assiri. 2019. "Health conditions for travellers to Saudi Arabia for the pilgrimage to Mecca (Hajj)-2015." Journal of epidemiology and global health 6 (1): 7-9.

Almond, Douglas. 2006. "Is the 1918 Influenza pandemic over? Long-term effects of in utero Influenza exposure in the post-1940 US population." Journal of Political Economy 114 (4): $672-712$.

Almond, Douglas, and Bhashkar Mazumder. 2011. "Health capital and the prenatal environment: the effect of Ramadan observance during pregnancy." American Economic Journal: Applied Economics 3 (4): 56-85.

Archibong, Belinda. 2019. "Explaining divergence in the long-term effects of precolonial centralization on access to public infrastructure services in Nigeria." World Development 121: $123-140$.

Archibong, Belinda, and Francis Annan. 2017. "Disease and Gender Gaps in Human Capital Investment: Evidence from Niger's 1986 Meningitis Epidemic." American Economic Review, Papers and Proceedings 107 (5): 530-35.

Archibong, Belinda, and Francis Annan. 2019. "Schooling in Sickness and in Health: The Effects of Epidemic Disease on Gender Inequality." CDEP-CGEG Working Paper No. 54 .

Bandiera, Oriana, Niklas Buehren, Markus P Goldstein, Imran Rasul, and Andrea Smurra. 2019. The Economic Lives of Young Women in the Time of Ebola: Lessons from an Empowerment Program. The World Bank. 
Basta, Nicole E, Abdoulaye Berthe, Mahamadou Keita, Uma Onwuchekwa, Boubou Tamboura, Awa Traore, Musa Hassan-King, Olivier Manigart, Maria Nascimento, James M Stuart et al. 2018. "Meningococcal carriage within households in the African meningitis belt: A longitudinal pilot study." Journal of Infection 76 (2): 140-148.

Beauchemin, Cris, and Philippe Bocquier. 2004. "Migration and urbanisation in Francophone West Africa: An overview of the recent empirical evidence." Urban Studies 41 (11): 22452272 .

Bhalotra, Sonia R, and Atheendar Venkataramani. 2015. "Shadows of the captain of the men of death: Early life health interventions, human capital investments, and institutions.".

Bleakley, Hoyt. 2007. "Disease and development: evidence from hookworm eradication in the American South." The Quarterly Journal of Economics 122 (1): 73-117.

Bloom, David E, and Ajay S Mahal. 1997. "Does the AIDS epidemic threaten economic growth?" Journal of Econometrics 77 (1): 105-124.

Bloom, David E, and Daniel Cadarette. 2019. "Infectious Disease Threats in the 21st Century: Strengthening the Global Response." Frontiers in immunology 10: 549.

Bloom, David E, David Canning et al. 2004. "Epidemics and economics." Interactions Between Global Change and Human Health (Scripta Varia 106: 304-331.

Boone, Peter. 1996. "Politics and the effectiveness of foreign aid." European Economic Review 40 (2): 289-329.

Bräutigam, Deborah A, and Stephen Knack. 2004. "Foreign aid, institutions, and governance in sub-Saharan Africa." Economic development and cultural change 52 (2): 255-285. 
Burgess, Robin, Remi Jedwab, Edward Miguel, Ameet Morjaria, and Gerard Padró i Miquel. 2015. "The value of democracy: evidence from road building in Kenya." American Economic Review 105 (6): 1817-51.

Burnside, Craig, and David Dollar. 2000. "Aid, policies, and growth." American economic review 90 (4): 847-868.

Chigudu, Simukai. 2019. "The politics of cholera, crisis and citizenship in urban Zimbabwe:"People were dying like flies"." African Affairs 118 (472): 413-434.

Chigudu, Simukai. 2020. The Political Life of an Epidemic: Cholera, Crisis and Citizenship in Zimbabwe. Cambridge University Press.

Colombini, Anaïs, Fernand Bationo, Sylvie Zongo, Fatoumata Ouattara, Ousmane Badolo, Philippe Jaillard, Emmanuel Seini, Bradford D Gessner, and Alfred Da Silva. 2009. "Costs for households and community perception of meningitis epidemics in Burkina Faso." Clinical Infectious Diseases 49 (10): 1520-1525.

Copeland, Daphne L, Ricardo Basurto-Davila, Wendy Chung, Anita Kurian, Daniel B Fishbein, Paige Szymanowski, Jennifer Zipprich, Harvey Lipman, Martin S Cetron, Martin I Meltzer et al. 2013. "Effectiveness of a school district closure for pandemic influenza A (H1N1) on acute respiratory illnesses in the community: a natural experiment." Clinical infectious diseases 56 (4): 509-516.

Deaton, Angus. 2003. "Health, inequality, and economic development." Journal of economic literature 41 (1): 113-158.

Deserrano, Erika, Aisha Nansamba, and Nancy Qian. 2020. "Aid Crowd-Out: The Effect of NGOs on Government-Provided Public Services." Working Paper . 
Dickens, Andrew. 2018. "Ethnolinguistic favoritism in african politics." American Economic Journal: Applied Economics 10 (3): 370-402.

Easterly, William. 2006. The white man's burden: why the West's efforts to aid the rest have done so much ill and so little good. Penguin Press New York.

Farmer, Paul. 1996. "Social inequalities and emerging infectious diseases." Emerging infectious diseases 2 (4): 259 .

Farmer, Paul. 2001. Infections and inequalities: The modern plagues. Univ of California Press.

Fenichel, Eli P. 2013. "Economic considerations for social distancing and behavioral based policies during an epidemic." Journal of health economics 32 (2): 440-451.

Francois, Patrick, Ilia Rainer, and Francesco Trebbi. 2015. "How is power shared in Africa?" Econometrica 83 (2): 465-503.

García-Pando, Carlos Pérez, Madeleine C Thomson, Michelle C Stanton, Peter J Diggle, Thomas Hopson, Rajul Pandya, Ron L Miller, and Stéphane Hugonnet. 2014. "Meningitis and climate: from science to practice." Earth Perspectives 1 (1): 14.

Geoffard, Pierre-Yves, and Tomas Philipson. 1996. "Rational epidemics and their public control." International economic review pp. 603-624.

Gould, Eric D, Victor Lavy, and M Daniele Paserman. 2011. "Sixty years after the magic carpet ride: The long-run effect of the early childhood environment on social and economic outcomes." The Review of Economic Studies 78 (3): 938-973.

Gyimah-Brempong, Kwabena. 2015. "Do African countries get health from health aid?" Journal of African Development 17 (2): 83-114. 
Habicht, Jean-Pierre, Charles Yarbrough, Reynaldo Martorell, RobertM Malina, and RobertE Klein. 1974. "Height and weight standards for preschool children: How relevant are ethnic differences in growth potential?" The Lancet 303 (7858): 611-615.

Henderson, Vernon, Adam Storeygard, and David N Weil. 2011. "A bright idea for measuring economic growth." American Economic Review 101 (3): 194-99.

Hodler, Roland, and Paul A Raschky. 2014. "Regional favoritism." The Quarterly Journal of Economics 129 (2): 995-1033.

Jayachandran, Seema, and Adriana Lleras-Muney. 2009. "Life Expectancy and Human Capital Investments." The Quarterly Journal of Economics 124 (1): 349-397.

Jayachandran, Seema, and Rohini Pande. 2017. "Why are Indian children so short? The role of birth order and son preference." American Economic Review 107 (9): 2600-2629.

Karachaliou, Andromachi, Andrew JK Conlan, Marie-Pierre Preziosi, and Caroline L Trotter. 2015. "Modeling long-term vaccination strategies with MenAfriVac in the African meningitis belt." Clinical Infectious Diseases 61 (suppl_5): S594-S600.

Kiszewski, Anthony, Andrew Mellinger, Andrew Spielman, Pia Malaney, Sonia Ehrlich Sachs, and Jeffrey Sachs. 2004. "A global index representing the stability of malaria transmission." The American journal of tropical medicine and hygiene 70 (5): 486-498.

Kotsadam, Andreas, Gudrun Østby, Siri Aas Rustad, Andreas Forø Tollefsen, and Henrik Urdal. 2018. "Development aid and infant mortality. Micro-level evidence from Nigeria." World Development 105: 59-69.

Krieger, Nancy. 2001. "Theories for social epidemiology in the 21st century: an ecosocial perspective." International journal of epidemiology 30 (4): 668-677. 
LaForce, F Marc, Neil Ravenscroft, Mamoudou Djingarey, and Simonetta Viviani. 2009. "Epidemic meningitis due to Group A Neisseria meningitidis in the African meningitis belt." Vaccine 27: B13-B19.

Lai, Rebecca, Jin Wu, Richard Harris, Allison McCann, Keith Collins, Derek Watkins, and Jugal Patel. 2020. "Coronavirus Map: Tracking the Spread of the Outbreak." The New York Times .

Leach, Melissa, Ian Scoones, and Andrew Stirling. 2010. "Governing epidemics in an age of complexity: Narratives, politics and pathways to sustainability." Global Environmental Change 20 (3): 369-377.

Lingani, Clément, Cassi Bergeron-Caron, James M Stuart, Katya Fernandez, Mamoudou H Djingarey, Olivier Ronveaux, Johannes C Schnitzler, and William A Perea. 2015. "Meningococcal meningitis surveillance in the African meningitis belt, 2004-2013." Clinical infectious diseases 61 (suppl_5): S410-S415.

Lingappa, Jairam R, Abdullah M Al-Rabeah, Tajammal Mustafa Rana Hajjeh, Adel Fatani, Tami Al-Bassam, Amira Badukhan, Abdulhafiz Turkistani, Nassen Al-Hamdan, Mohamed Al-Jeffri, Yaqoub Al Mazrou et al. 2003. "Serogroup W-135 meningococcal disease during the Hajj, 2000." Emerging infectious diseases 9 (6): 665.

Memish, ZA. 2010. "The Hajj: communicable and non-communicable health hazards and current guidance for pilgrims." Eurosurveillance 15 (39): 19671.

Michalopoulos, Stelios, and Elias Papaioannou. 2013. "Pre-colonial ethnic institutions and contemporary African development." Econometrica 81 (1): 113-152.

Miguel, Edward, and Michael Kremer. 2004. "Worms: identifying impacts on education and health in the presence of treatment externalities." Econometrica 72 (1): 159-217. 
Moyo, Dambisa. 2009. Dead aid: Why aid is not working and how there is a better way for Africa. Macmillan.

Murdock, George Peter. 1967. "Ethnographic atlas.".

Ndikumana, Léonce, and Lynda Pickbourn. 2017. "The impact of foreign aid allocation on access to social services in sub-Saharan Africa: The case of water and sanitation." World Development 90: 104-114.

Novak, Ryan T, Olivier Ronveaux, André F Bita, Honoré Flavien Aké, Fernanda C Lessa, Xin Wang, Ado M Bwaka, and LeAnne M Fox. 2019. "Future directions for meningitis surveillance and vaccine evaluation in the meningitis belt of sub-Saharan Africa." The Journal of infectious diseases 220 (Supplement_4): S279-S285.

Nunn, Nathan, and Nancy Qian. 2014. "US food aid and civil conflict." American Economic Review 104 (6): 1630-66.

Odokonyero, Tonny, Alex Ijjo, Robert Marty, Tony Muhumuza, and Godfrey Owot Moses. 2015. Subnational Perspectives on Aid Effectiveness: Impact of Aid on Health Outcomes in Uganda. Technical report.

Öhler, Hannes, Mario Negre, Lodewijk Smets, Renzo Massari, and Željko Bogetić. 2017. "Putting your money where your mouth is: geographic targeting of World Bank projects to the bottom 40 percent." World Bank Policy Research Working Paper.

Organization, World Health. 2018. "Meningococcal meningitis. Fact sheet 2018.".

Organization, World Health. 2019. "WHO recommendations for routine immunizations summary tables.".

Organization, World Health. 2020. "WHO Humanitarian Health Action, Definitions: emergencies." https://www. who. int/hac/about/definitions/en/. 
Oster, Emily. 2005. "Sexually transmitted infections, sexual behavior, and the HIV/AIDS epidemic." The Quarterly Journal of Economics 120 (2): 467-515.

Perez Garcia Pando, Carlos, Michelle C Stanton, Peter J Diggle, Sylwia Trzaska, Ron L Miller, Jan P Perlwitz, José M Baldasano, Emilio Cuevas, Pietro Ceccato, Pascal Yaka et al. 2014. "Soil dust aerosols and wind as predictors of seasonal meningitis incidence in Niger." Environmental Health Perspectives .

Philipson, Tomas. 1999. Economic epidemiology and infectious diseases. Technical report National Bureau of Economic Research.

Shafi, Shuja, Robert Booy, Elizabeth Haworth, Harunor Rashid, and Ziad A Memish. 2008. "Hajj: health lessons for mass gatherings." Journal of infection and public health 1 (1): $27-32$.

Yaka, Pascal, Benjamin Sultan, Hélène Broutin, Serge Janicot, Solenne Philippon, and Nicole Fourquet. 2008. "Relationships between climate and year-to-year variability in meningitis outbreaks: a case study in Burkina Faso and Niger." International Journal of Health Geographics 7 (1): 34 .

Yezli, Saber, Abdulaziz A Bin Saeed, Abdullah M Assiri, Rafat F Alhakeem, Muslim A Yunus, Abdulhafiz M Turkistani, Robert Booy, and Badriah M Alotaibi. 2016. "Prevention of meningococcal disease during the Hajj and Umrah mass gatherings: past and current measures and future prospects." International Journal of Infectious Diseases 47: 71-78.

Youde, Jeremy. 2017. "Global health governance in international society." Global Governance $23(4): 583-600$.

Zhang, Sheng, MengYuan Diao, Wenbo Yu, Lei Pei, Zhaofen Lin, and Dechang Chen. 2020. "Estimation of the reproductive number of Novel Coronavirus (COVID-19) and the prob- 
able outbreak size on the Diamond Princess cruise ship: A data-driven analysis." International Journal of Infectious Diseases 93: 201-204.

Zunt, Joseph Raymond, Nicholas J Kassebaum, Natacha Blake, Linda Glennie, Claire Wright, Emma Nichols, Foad Abd-Allah, Jemal Abdela, Ahmed Abdelalim, Abdu A Adamu et al. 2018. "Global, regional, and national burden of meningitis, 1990-2016: a systematic analysis for the Global Burden of Disease Study 2016." The Lancet Neurology 17 (12): 1061-1082. 


\section{A Appendix (For Online Publication)}

\section{Contents}

1 Introduction 2

2 Epidemics and the Epidemiology of Infectious Disease: Evidence from the $\begin{array}{lr}\text { Meningitis Belt } & 8\end{array}$

2.1 The Meningitis Belt . . . . . . . . . . . . . . . . . . 9

2.1 .1 Hajj and Meningitis Epidemics _... . . . . . . . . . . 12

3 Description of Data: Economic Activity, Child Health, Aid and Regional $\begin{array}{ll}\text { Favoritism } & 13\end{array}$

3.1 Meningitis Cases . . . . . . . . . . . . . . . . . . . . . . . . . 14

3.2 Night Lights . . . . . . . . . . . . . . . . . . . . . . . . . . . 15

3.3 Child Health . . . . . . . . . . . . . . . . . . . . . . . . . . 15

3.4 World Bank Aid Data . . . . . . . . . . . . . . . . . . 17

3.5 Regional Favoritism . . . . . . . . . . . . . . . . . . . . . . 18

4 Estimating the Effects of Meningitis Epidemics on Economic Activity and $\begin{array}{lr}\text { Child Health Outcomes } & 18\end{array}$

4.1 Intuition and Sources of Variation . . . . . . . . . . . . 18

4.2 Model Specification . . . . . . . . . . . . . . . . . . . . 19

4.3 Balance and Validity of Design $\ldots \ldots \ldots \ldots 21$

4.4 Instrumental Variables Strategy . . . . . . . . . . . . . . . . . . 21

4.5 Results for Night Light Density . . . . . . . . . . . . . . . . . . . 22

4.6 Results for Child Health Outcomes . . . . . . . . . . . . . . . . . . . 23

4.7 Instrumental Variable Estimates: Night Light Density . . . . . . . . . . . 25 
5.1 How World Bank Projects are Approved and Funded . . . . . . . . . . . . 27

5.2 Results: Health Project and Non Health Funding in Epidemic vs Non-Epidemic

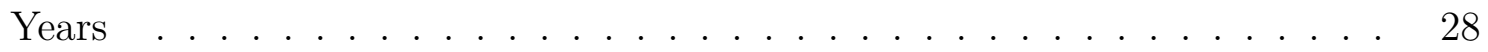

6 Domestic Institutions: Regional Favoritism and Epidemics 29

6.1 Within Niger Evidence . . . . . . . . . . . . . . . . . . . . . . . . . . . . 29

6.2 Regional Favoritism Results . . . . . . . . . . . . . . . . . . . 30

$\begin{array}{lll}7 & \text { Conclusions } & 31\end{array}$

$\begin{array}{ll}\text { A Appendix (For Online Publication) } & 66\end{array}$

A.1 Additional Tables, Robustness Checks . . . . . . . . . . . . . . . . 70

A.2 Hajj Months, $1986-2008 \ldots \ldots \ldots 7$. . . . . . . . . . . . 77

\section{List of Figures}

1 Countries in the African Meningitis Belt . . . . . . . . . . . . . 33

2 Countries and districts in study region $\ldots \ldots \ldots 34$

3 Mean weekly meningitis cases per district over study region, with epidemic years specified in brackets . . . . . . . . . . . . . . . 34

4 Spatial distribution of meningitis shock over study districts for selected years,

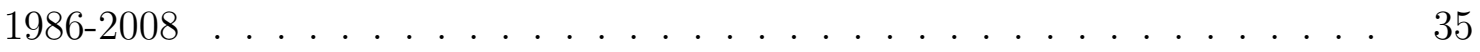

5 Locations of World Bank aid projects for countries and districts in study region over study years . . . . . . . . . . . . . . 36

6 Health spending statistics across regions, 2016. Source: World Bank . . . . . 37

$7 \quad$ Meningitis Epidemic Curves (Niger) . . . . . . . . . . . . . . . . 38 
8 Stochastic dominance: Log night light density is higher in meningitis shock districts during declared epidemic year (EY). Lower in non-epidemic years .

9 More economic activity, Less stunting and underweight children currently, if born in high meningitis shock districts but year was declared an epidemic year. In high shock, non epidemic year districts, lowered economic activity, and more stunting and underweight. Potential crowd-out of routine vaccines during epidemic years . . . . . . . . . . . . . . . . . . 41

10 World Bank project approval example snapshot . . . . . . . . . . . . . 47

11 Top 5 World Bank health and non-health projects funded by project title in epidemic and non-epidemic years . . . . . . . . . . . . . .

A1 More health projects approved and more money committed and disbursed to health projects overall during epidemic years, less to non-health projects. Difficult to target health projects to high shock districts since locations decided ex-ante and health projects are only $12 \%$ of aid projects. Redistribution of resources away from non-health projects to health projects so less non-health projects and more health projects funded during epidemic years. . . . . . .

A2 Health aid projects started during the epidemic year are rated more poorly than health aid projects started during the non-epidemic year . . . . . . . . 71

A3 High shock districts that share the same ethnicity as the president see more economic activity than non-coethnic districts. Children born in high shock coethnic districts have less current underweight, stunting, more routine vaccine if born during epidemic year, than non-coethnic districts. No ethnicity effects in non-epidemic year for child outcomes . . . . . . . . . . . . . . . . . 72

\section{List of Tables}

1 Summary Statistics, Africa . . . . . . . . . . . . . . 
2 WHO recommended vaccination schedule . . . . . . . . . . . . . 39

3 Balance on geographic and institutional characteristics . . . . . . . . . . 40

4 Effect of meningitis shock on economic activity in epidemic vs non-epidemic

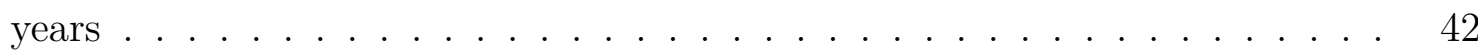

5 Effect of meningitis shock on child current weight and height outcomes in epidemic vs non-epidemic years . . . . . . . . . . . . . . . . . . 43

6 Effect of meningitis shock on at birth (bcg, polio) vs non-at birth recommended (dpt, measles) child vaccinations . . . . . . . . . . . . . . 44

7 Effect of meningitis shock on infant mortality and number of total child vaccinations in epidemic vs non-epidemic years . . . . . . . . . . . . . . . 45

8 First and second-stage estimates for interacted Share Muslim x Hajj instrument and comparisons with OLS results for night light density . . . . . . . 46

9 Effect of meningitis shock and epidemic year on share of World Bank aid health vs non-health projects approved . . . . . . . . . . . . . . 47

10 Effect of meningitis shock and epidemic year on amount committed and disbursed to World Bank aid projects . . . . . . . . . . . . . . . . 48

11 Effect of meningitis shock and epidemic year on independent rating of World Bank aid projects . . . . . . . . . . . . . . . . . . . 49

12 Effect of meningitis shock on night light density outcomes by World Bank aid share of health projects, and total committed and disbursed aid . . . . . . . 50

13 Effect of meningitis shock on economic activity in epidemic vs non-epidemic years, co-ethnic vs non-co-ethnic with president districts, Niger . . . . . . 52

14 Split sample: Effect of meningitis shock on economic activity in epidemic vs non-epidemic years, co-ethnic vs non-co-ethnic with president districts, Niger 
15 Split sample: Effect of meningitis shock on infant mortality and child current weight and height outcomes in epidemic vs. non-epidemic years, co-ethnic vs non co-ethnic with president districts, Niger . . . . . . . . . . . . 54

16 Split sample: Effect of meningitis shock on child vaccination outcomes in epidemic vs non-epidemic years, co-ethnic vs non co-ethnic with president districts, Niger . . . . . . . . . . . . . . . . . . 55

A1 Health expenditure statistics by region, 2016. Source: World Bank . . . . . . 71

A2 Effect of meningitis shock on child mortality, current weight and height outcomes in epidemic years, co-ethnic vs non co-ethnic with president districts,

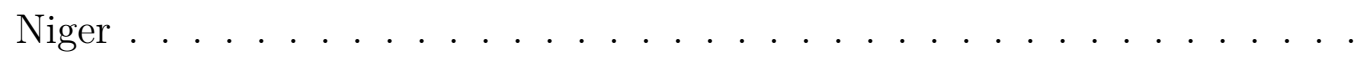

A3 Effect of meningitis shock on at birth (bcg, polio) vs non-at birth recommended (dpt, measles) vaccinations in epidemic years, co-ethnic vs non coethnic with president districts, Niger . . . . . . . . . . . . . . 74

A4 Effect of meningitis shock on infant mortality, current weight and height outcomes in non-epidemic years, co-ethnic vs non co-ethnic with president dis-

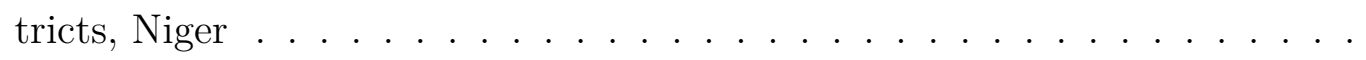

A5 Effect of meningitis shock on at birth (bcg, polio) vs non-at birth recommended (dpt, measles) vaccinations in non-epidemic years, co-ethnic vs non co-ethnic with president districts, Niger . . . . . . . . . . . 76

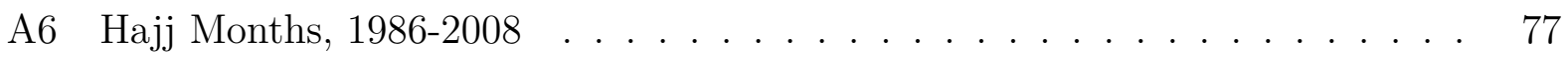

\section{A.1 Additional Tables, Robustness Checks}


Table A1: Health expenditure statistics by region, 2016. Source: World Bank

\begin{tabular}{|c|c|c|c|c|c|c|c|c|c|c|c|}
\hline Variable (2016) & Benin & Burkina Faso & Cameroon & Ghana & Mali & Niger & Nigeria & Togo & Study mean & Africa mean & World mean \\
\hline Health spending ( $\%$ of GDP) & 3.9 & 6.8 & 4.7 & 4.4 & 3.8 & 6.2 & 3.6 & 6.6 & 5 & 5.6 & 10 \\
\hline Health spending per capita (USD) & 30 & 41 & 64 & 68 & 30 & 23 & 79 & 39 & 47 & 119 & 1,026 \\
\hline Government spending per capita (USD) & 6 & 16 & 9 & 26 & 9 & 6 & 10 & 8 & 11 & 59 & 763 \\
\hline Government spending per capita (\% of GDP) & 0.8 & 2.7 & 0.6 & 1.7 & 1.2 & 1.5 & 0.5 & 1.3 & 1.1 & 1.3 & 7.4 \\
\hline Donor spending (\% of health spending) & 30 & 23 & 9 & 13 & 32 & 13 & 10 & 21 & 19 & 20 & \\
\hline Out-of-pocket (\% of health spending) & 43 & 31 & 70 & 38 & 35 & 59 & 75 & 50 & 50 & 36 & 19 \\
\hline Out-of-pocket spending per capita (USD) & 13 & 13 & 45 & 26 & 11 & 13 & 60 & 20 & 25 & 36 & 190 \\
\hline Out-of-pocket (\% of GDP) & 1.7 & 2.1 & 3.3 & 1.7 & 1.3 & 3.6 & 2.7 & 3.4 & 2.4 & 0.8 & 1.9 \\
\hline
\end{tabular}

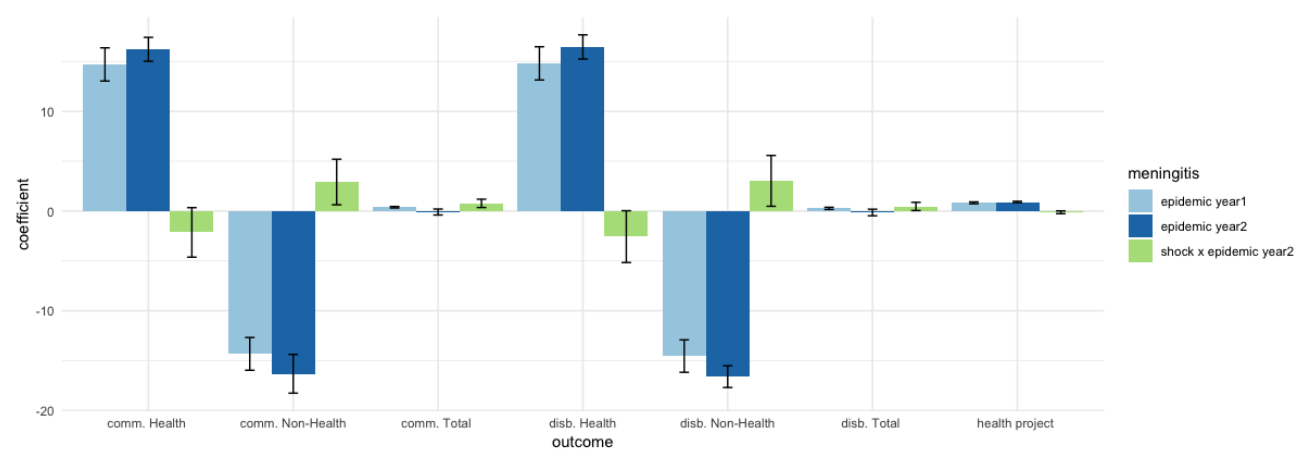

Figure A1: More health projects approved and more money committed and disbursed to health projects overall during epidemic years, less to non-health projects. Difficult to target health projects to high shock districts since locations decided ex-ante and health projects are only $12 \%$ of aid projects. Redistribution of resources away from non-health projects to health projects so less non-health projects and more health projects funded during epidemic years.

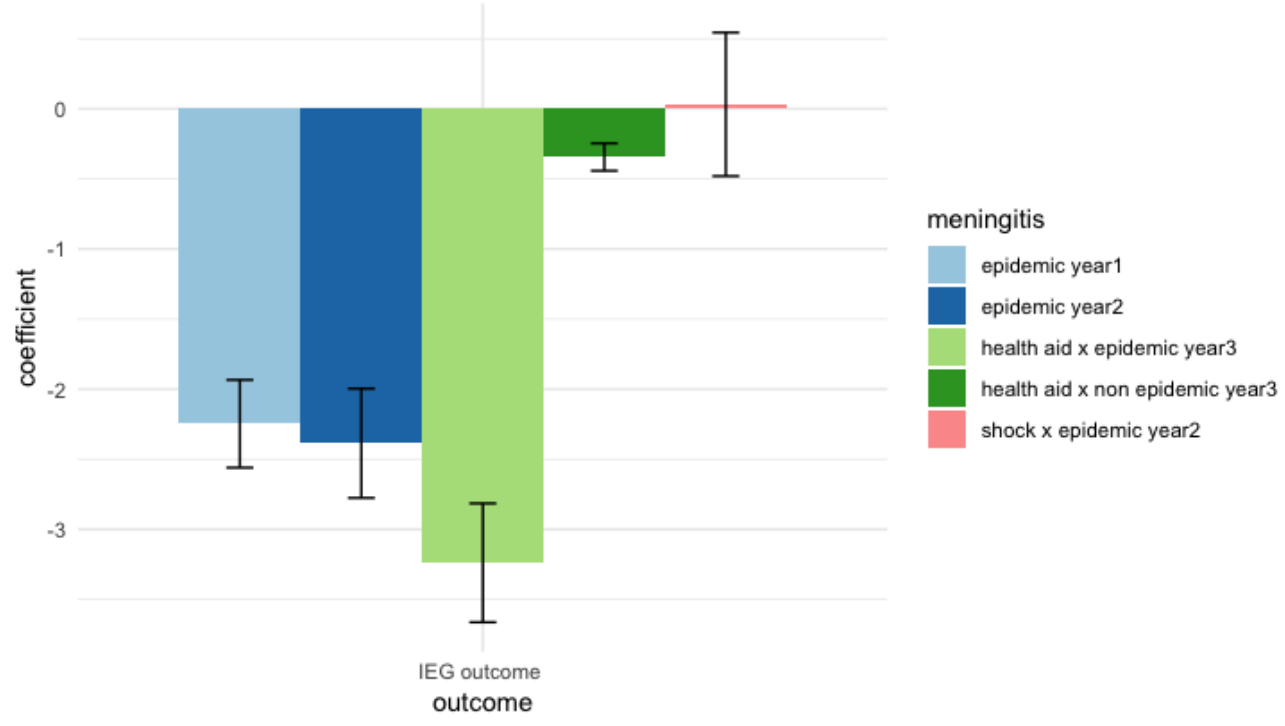

Figure A2: Health aid projects started during the epidemic year are rated more poorly than health aid projects started during the non-epidemic year 


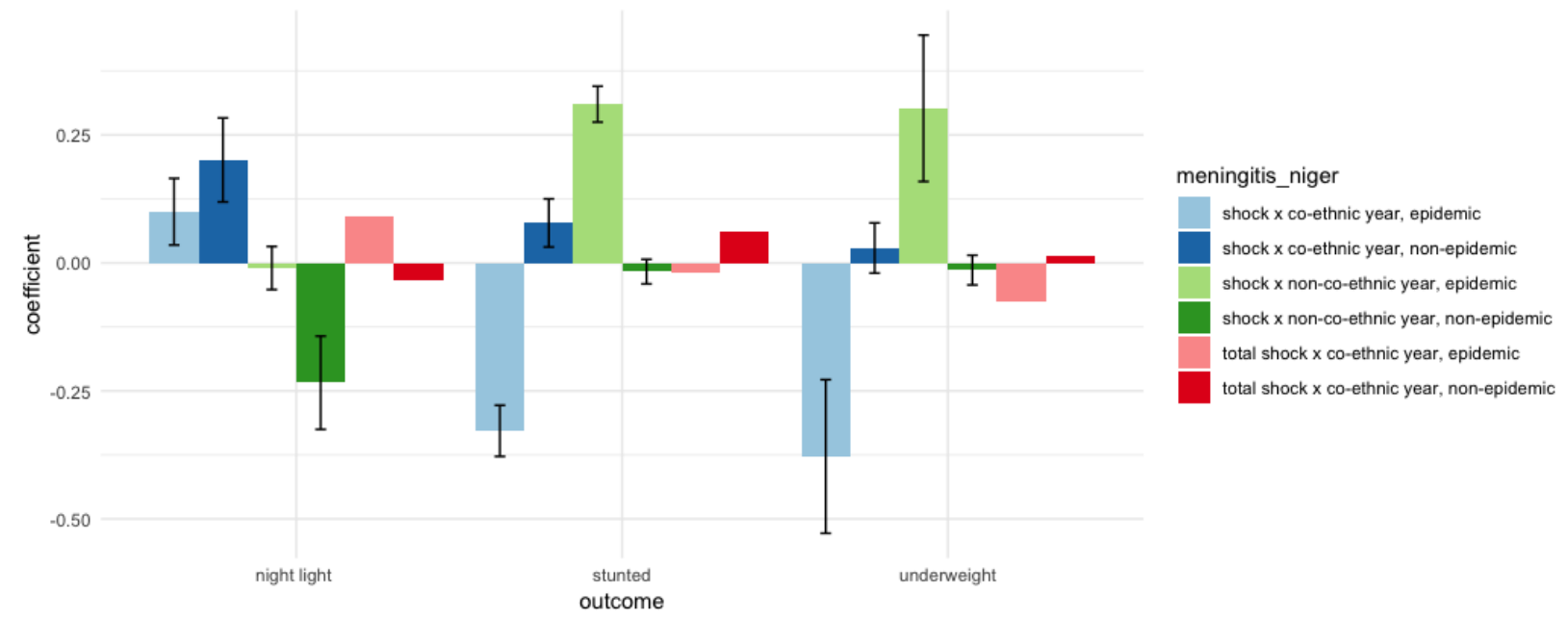

Figure A3: High shock districts that share the same ethnicity as the president see more economic activity than non-coethnic districts. Children born in high shock co-ethnic districts have less current underweight, stunting, more routine vaccine if born during epidemic year, than non-coethnic districts. No ethnicity effects in non-epidemic year for child outcomes 
Table A2: Effect of meningitis shock on child mortality, current weight and height outcomes in epidemic years, co-ethnic vs non co-ethnic with president districts, Niger

\begin{tabular}{|c|c|c|c|c|c|}
\hline & $\begin{array}{c}\text { Mortality } \\
\text { (1) }\end{array}$ & $\begin{array}{c}\text { WFA z } \\
(2)\end{array}$ & $\begin{array}{c}\text { Underweight } \\
\text { (3) }\end{array}$ & $\begin{array}{c}\text { HFA z } \\
(4)\end{array}$ & $\begin{array}{c}\text { Stunted } \\
(5)\end{array}$ \\
\hline Meningitis shock & $\begin{array}{c}0.044 \\
(0.029)\end{array}$ & $\begin{array}{c}-0.540^{* *} \\
(0.208)\end{array}$ & $\begin{array}{r}0.295^{*} \\
(0.169)\end{array}$ & $\begin{array}{r}-0.912^{*} \\
(0.543)\end{array}$ & $\begin{array}{l}0.302^{* * *} \\
(0.051)\end{array}$ \\
\hline Same ethnicity & $\begin{array}{c}-0.002 \\
(0.038)\end{array}$ & $\begin{array}{c}-0.637^{* * *} \\
(0.199)\end{array}$ & $\begin{array}{c}0.382^{* *} \\
(0.165)\end{array}$ & $\begin{array}{c}-1.105^{* *} \\
(0.531)\end{array}$ & $\begin{array}{l}0.421^{* * *} \\
(0.047)\end{array}$ \\
\hline Meningitis shock x Same ethnicity & $\begin{array}{r}-0.078^{*} \\
(0.045)\end{array}$ & $\begin{array}{l}0.682^{* * *} \\
(0.215)\end{array}$ & $\begin{array}{c}-0.372^{* *} \\
(0.174)\end{array}$ & $\begin{array}{r}0.975^{*} \\
(0.534)\end{array}$ & $\begin{array}{c}-0.321^{* * *} \\
(0.061)\end{array}$ \\
\hline Mean of outcome & 0.349 & -2.244 & 0.605 & -2.261 & 0.568 \\
\hline Mother's controls & Yes & Yes & Yes & Yes & Yes \\
\hline District FE & Yes & Yes & Yes & Yes & Yes \\
\hline Year of birth FE & Yes & Yes & Yes & Yes & Yes \\
\hline Year FE* & Yes & Yes & Yes & Yes & Yes \\
\hline Observations & 2,272 & 1,844 & 1,844 & 1,844 & 1,844 \\
\hline
\end{tabular}

Notes: Regressions estimated by OLS. Robust standard errors in parentheses clustered by district. Dependent variables are child outcomes described in text from Niger. Meningitis shock is Z score indicator based on district level mean as described in text. Mother's controls include mother's age at birth and level of education. Year fixed effects are dropped for underweight and stunted outcomes in epidemic years due to not enough levels in the epidemic years. ${ }^{* * *}$ Significant at the 1 percent level, ${ }^{* *}$ Significant at the 5 percent level, ${ }^{*}$ Significant at the 10 percent level. 
Table A3: Effect of meningitis shock on at birth (bcg, polio) vs non-at birth recommended (dpt, measles) vaccinations in epidemic years, co-ethnic vs non co-ethnic with president districts, Niger

\begin{tabular}{|c|c|c|c|c|c|}
\hline & $\begin{array}{c}\text { BCG } \\
(1)\end{array}$ & $\begin{array}{c}\text { Nos. Polio } \\
(2)\end{array}$ & $\begin{array}{c}\text { DPT } \\
(3)\end{array}$ & $\begin{array}{c}\text { Measles } \\
(4)\end{array}$ & $\begin{array}{c}\text { Total } \\
(5)\end{array}$ \\
\hline Meningitis shock & $\begin{array}{c}-0.019 \\
(0.061)\end{array}$ & $\begin{array}{c}-0.202^{* *} \\
(0.077)\end{array}$ & $\begin{array}{c}-0.152^{* *} \\
(0.106)\end{array}$ & $\begin{array}{c}0.047 \\
(0.201)\end{array}$ & $\begin{array}{c}-0.301 \\
(0.173)\end{array}$ \\
\hline Same ethnicity & $\begin{array}{c}-0.160^{* *} \\
(0.066)\end{array}$ & $\begin{array}{c}-0.961^{* * *} \\
(0.071)\end{array}$ & $\begin{array}{c}-1.148^{* * *} \\
(0.107)\end{array}$ & $\begin{array}{r}-0.170 \\
(0.202)\end{array}$ & $\begin{array}{c}-2.309^{* * *} \\
(0.330)\end{array}$ \\
\hline Meningitis shock x Same ethnicity & $\begin{array}{r}-0.006 \\
(0.070)\end{array}$ & $\begin{array}{c}0.185^{* *} \\
(0.088)\end{array}$ & $\begin{array}{c}0.143 \\
(0.104)\end{array}$ & $\begin{array}{r}-0.067 \\
(0.209)\end{array}$ & $\begin{array}{c}0.233 \\
(0.330)\end{array}$ \\
\hline Mean of outcome & 0.582 & 1.422 & 1.362 & 0.475 & 3.843 \\
\hline Mother's controls & Yes & Yes & Yes & Yes & Yes \\
\hline District FE & Yes & Yes & Yes & Yes & Yes \\
\hline Year of birth FE & Yes & Yes & Yes & Yes & Yes \\
\hline Year $\mathrm{FE}^{*}$ & Yes & Yes & Yes & Yes & Yes \\
\hline Observations & 2,066 & 2,059 & 2,049 & 2,034 & 2,016 \\
\hline
\end{tabular}

Notes: Regressions estimated by OLS. Robust standard errors in parentheses clustered by district. Dependent variables are child vaccination outcomes described in text from Niger. Meningitis shock is Z score indicator based on district level mean as described in text. Mother's controls include mother's age at birth and level of education. Year fixed effects are dropped in the model due to not enough levels in the epidemic years. ${ }^{* * *}$ Significant at the 1 percent level, ${ }^{*}$ Significant at the 5 percent level, ${ }^{*}$ Significant at the 10 percent level. 
Table A4: Effect of meningitis shock on infant mortality, current weight and height outcomes in non-epidemic years, co-ethnic vs non co-ethnic with president districts, Niger

\begin{tabular}{|c|c|c|c|c|c|}
\hline & $\begin{array}{c}\text { Mortality } \\
\text { (1) }\end{array}$ & $\begin{array}{c}\text { WFA z } \\
(2)\end{array}$ & $\begin{array}{c}\text { Underweight } \\
\text { (3) }\end{array}$ & $\begin{array}{c}\text { HFA z } \\
(4)\end{array}$ & $\begin{array}{c}\text { Stunted } \\
(5)\end{array}$ \\
\hline Meningitis shock & $\begin{array}{c}0.024 \\
(0.027)\end{array}$ & $\begin{array}{c}-0.036 \\
(0.085)\end{array}$ & $\begin{array}{c}-0.014 \\
(0.027)\end{array}$ & $\begin{array}{c}0.012 \\
(0.076)\end{array}$ & $\begin{array}{c}-0.017 \\
(0.024)\end{array}$ \\
\hline Same ethnicity & $\begin{array}{c}0.020 \\
(0.041)\end{array}$ & $\begin{array}{c}0.019 \\
(0.056)\end{array}$ & $\begin{array}{c}-0.035 \\
(0.022)\end{array}$ & $\begin{array}{r}0.148^{*} \\
(0.078)\end{array}$ & $\begin{array}{c}-0.038 \\
(0.023)\end{array}$ \\
\hline Meningitis shock x Same ethnicity & $\begin{array}{c}-0.052 \\
(0.054)\end{array}$ & $\begin{array}{c}0.065 \\
(0.248)\end{array}$ & $\begin{array}{c}0.028 \\
(0.048)\end{array}$ & $\begin{array}{r}-0.191 \\
(0.256)\end{array}$ & $\begin{array}{c}0.077 \\
(0.047)\end{array}$ \\
\hline Mean of outcome & 0.339 & -1.527 & 0.378 & -1.309 & 0.316 \\
\hline Mother's controls & Yes & Yes & Yes & Yes & Yes \\
\hline District FE & Yes & Yes & Yes & Yes & Yes \\
\hline Year of birth FE & Yes & Yes & Yes & Yes & Yes \\
\hline Year FE & Yes & Yes & Yes & Yes & Yes \\
\hline Observations & 4,294 & 5,993 & 5,993 & 5,993 & 5,993 \\
\hline
\end{tabular}

Notes: Regressions estimated by OLS. Robust standard errors in parentheses clustered by district. Dependent variables are child outcomes described in text from Niger. Meningitis Shock is Z score indicator based on district level mean as described in text. Mother's controls include mother's age at birth and level of education. ${ }^{* * *}$ Significant at the 1 percent level, ${ }^{* *}$ Significant at the 5 percent level, ${ }^{*}$ Significant at the 10 percent level. 
Table A5: Effect of meningitis shock on at birth (bcg, polio) vs non-at birth recommended (dpt, measles) vaccinations in non-epidemic years, co-ethnic vs non co-ethnic with president districts, Niger

\begin{tabular}{|c|c|c|c|c|c|}
\hline & $\begin{array}{c}\text { BCG } \\
(1)\end{array}$ & $\begin{array}{c}\text { Nos. Polio } \\
(2)\end{array}$ & $\begin{array}{c}\text { DPT } \\
(3)\end{array}$ & $\begin{array}{c}\text { Measles } \\
(4)\end{array}$ & $\begin{array}{c}\text { Total } \\
(5)\end{array}$ \\
\hline Meningitis shock & $\begin{array}{c}0.003 \\
(0.027)\end{array}$ & $\begin{array}{c}0.086 \\
(0.082)\end{array}$ & $\begin{array}{c}0.091 \\
(0.083)\end{array}$ & $\begin{array}{c}0.007 \\
(0.031)\end{array}$ & $\begin{array}{c}0.178 \\
(0.186)\end{array}$ \\
\hline Same ethnicity & $\begin{array}{c}-0.008 \\
(0.034)\end{array}$ & $\begin{array}{c}0.041 \\
(0.115)\end{array}$ & $\begin{array}{c}0.043 \\
(0.117)\end{array}$ & $\begin{array}{c}0.054 \\
(0.046)\end{array}$ & $\begin{array}{c}0.142 \\
(0.275)\end{array}$ \\
\hline Meningitis shock x Same ethnicity & $\begin{array}{c}-0.059 \\
(0.056)\end{array}$ & $\begin{array}{c}-0.227 \\
(0.175)\end{array}$ & $\begin{array}{c}-0.203 \\
(0.173)\end{array}$ & $\begin{array}{c}-0.048 \\
(0.050)\end{array}$ & $\begin{array}{c}-0.467 \\
(0.387)\end{array}$ \\
\hline Mean of outcome & 0.460 & 0.933 & 0.946 & 0.284 & 2.620 \\
\hline Mother's controls & Yes & Yes & Yes & Yes & Yes \\
\hline District FE & Yes & Yes & Yes & Yes & Yes \\
\hline Year of birth FE & Yes & Yes & Yes & Yes & Yes \\
\hline Year FE & Yes & Yes & Yes & Yes & Yes \\
\hline Observations & 8,858 & 8,870 & 8,865 & 8,832 & 8,825 \\
\hline
\end{tabular}

Notes: Regressions estimated by OLS. Robust standard errors in parentheses clustered by district. Dependent variables are child vaccination outcomes described in text from Niger. Meningitis shock is Z score indicator based on district level mean as described in text. Mother's controls include mother's age at birth and level of education. ${ }^{* * *}$ Significant at the 1 percent level, ${ }^{* *}$ Significant at the 5 percent level, ${ }^{*}$ Significant at the 10 percent level. 


\section{A.2 Hajj Months, 1986-2008}

Table A6: Hajj Months, 1986-2008

\begin{tabular}{ccc}
\hline \hline & year & hajj month \\
\hline 1 & 1986 & august \\
2 & 1987 & august \\
3 & 1988 & july \\
4 & 1989 & july \\
5 & 1990 & july \\
6 & 1991 & june \\
7 & 1992 & june \\
8 & 1993 & june \\
9 & 1994 & may \\
10 & 1995 & may \\
11 & 1996 & april \\
12 & 1997 & april \\
13 & 1998 & april \\
14 & 1999 & march \\
15 & 2000 & march \\
16 & 2001 & march \\
17 & 2002 & february \\
18 & 2003 & february \\
19 & 2004 & february \\
20 & 2005 & january \\
21 & 2006 & january \\
22 & 2007 & december \\
23 & 2008 & december \\
\hline & &
\end{tabular}

